Estudios Fronterizos, año I, núm. 2, septiembre-diciembre de 1983, pp. 13-57

\title{
Migración y fuerza de trabajo en la frontera norte de México
}

\author{
Guadalupe Beatriz Acuña de Peña \\ Instituto de Investigaciones Sociales \\ Universidad Autónoma de Baja California
}

\section{Resumen}

Este estudio nos revela un aspecto de las relaciones internacionales entre México y Estados Unidos en el ámbito fronterizo, lo cual nos permite entender la dinámica de dichas relaciones. El centro de esta investigación son los transmigrantes residentes de Mexicali que realizan labores agrícolas en el Valle Imperial, California, ya que la agricultura es la actividad económica fundamental de la región y, coincidentemente, de todos los transmigrantes a lo largo de la frontera. Este tema, poco abordado en las investigaciones de la frontera, nos parece indispensable conocerlo para comprender la vida fronteriza del norte de México, pues más del 85\% de la mano de obra agrícola empleada en este valle proviene de la ciudad de Mexicali (Baja California, México). Del estudio de la transmigración (commuting) se derivan prácticas inherentes a cada zona fronteriza que afectan y actúan de manera diferente a ambos lados de la frontera. Finalmente, la transmigración nos descubre una nueva fuerza de trabajo importante no sólo para los Estados Unidos, sino también para México, especialmente en los momentos de crisis que atraviesa el país.

Palabras clave: migración, fuerza de trabajo, transmigrantes agrícolas, Valle Imperial, Mexicali.

\section{Abstract}

This research reveals an aspect of the international relations between Mexico and the United States in the border scenery that helps us to understand its special dynamics. Agriculture is the main economical activity of this region, and also for all trans-migrants along the border. For this reason, the targets of this study are those trans-migrants, who are residents of Mexicali performing agricultural jobs at the Imperial Valley. Too few researches have been developed on this topic; however, it is important for us to learn more about it to get a better understanding of the border life by the North of Mexico, because more than 85\% farm manpower employed in this valley comes from Mexicali (Baja California, México). Resulting from the transmigrants commuting research, there are many and diverse activities affecting and acting in different form at both sides of the border. Finally, migration unveils a new labor force that is important not just for the United States, but mainly during the critical times that Mexico is living.

Keywords: migration, work force, agriculture transmigrants, Imperial Valley, Mexicali. 


\title{
MIGRACION Y FUERZA DE TRABAJO EN LA FRONTERA NORTE DE MEXICO
}

\author{
Por \\ Gpe. Beatriz Acuña de Peña \\ Licenciada en Sociología. Investigadora \\ del Instituto de Investigaciones Sociales - UABC
}

\section{INTRODUCCION}

\section{La importancia del fenómeno}

La migración hacia los Estados Unidos ha sido uno de los temas que más interés y controversia ha suscitado entre los especialistas en la materia y la sociedad en general en las últimas décadas. De las diversas formas que han tomado los flujos migratorios hacia el vecino país, dos han concentrado la atención y han sido motivo de amplios trabajos: los braceros y los indocumentados. I Sin embargo, existe una tercera forma de migración hacia los Estados Unidos que desafortunadamente ha sido muy desatendida por los estudiosos mexicanos y escasamente abordada por los extranjeros. El tema, cuando ha sido enfocado, ha recibido un tratamiento con frecuencia general y poco profundo. 2 La modalidad migratoria a que hacemos referencia es la transmigración, fenómeno que ha formado parte de la vida de la frontera México-Estados Unidos desde principios de siglo y que no obstante su impor tancia, ha escapado al análisis de quienes se interesan en los flujos migratorios internacionales y en el conocimiento de los problemas de la frontera norte de México.

Esta práctica migratoria está encarnada por los commuters, como los califica el Servicio de Inmigración y Naturalización de los Estados Unidos, a quienes llamamos transmigrantes. Son éstos residentes de la frontera mexicana (o canadiense) que cruzan diariamente, o por temporadas, a trabajar en los Estados Unidos en forma legal 3 .

La importancia del estudio de esta modalidad migratoria radica, de una parte, en que nos revela un aspecto de las relaciones internacionales entre México y Estados Unidos, tal y como se manifiestan a nivel de la frontera, lo cual nos permite entender la dinámica de dichas relaciones. Por otra parte, del estudio de la transmigración se derivan implicaciones prácticas inherentes a cada zona fronteriza, que afectan y actúan de manera diferente a ambos lados de la frontera, las cuales es preciso conocer si pretendemos estar en posibilidades de prever. atender o aprovechar las consecuencias que de ella se derivan. Por último, la transmigración nos descubre una nueva fuerza de trabajo

1 Es bien conocida la extensa obra de Jorge Bustamante, Ernesto Galarza, Wayne Cornelius, Manuel Gamio, Raúl Fernández entre otros.

2 Entre los autores que la investigación nos permitió revisar se encuentran: Alicia Castellanos, Jorge Bustamante y Raúl Fernández. que más bien se limitan a señalar el fenómeno que a profundizar en él. En cuanto a trabajos extranjeros, destacan los de North y Houston, Roger La Broucherie y Stanley Knebel que han analizado aspectos concretos del fenómeno.

3 Más adelante se abundará en la definición y status legal de estos trabajadores. 
RIVERSIDE COUNTY

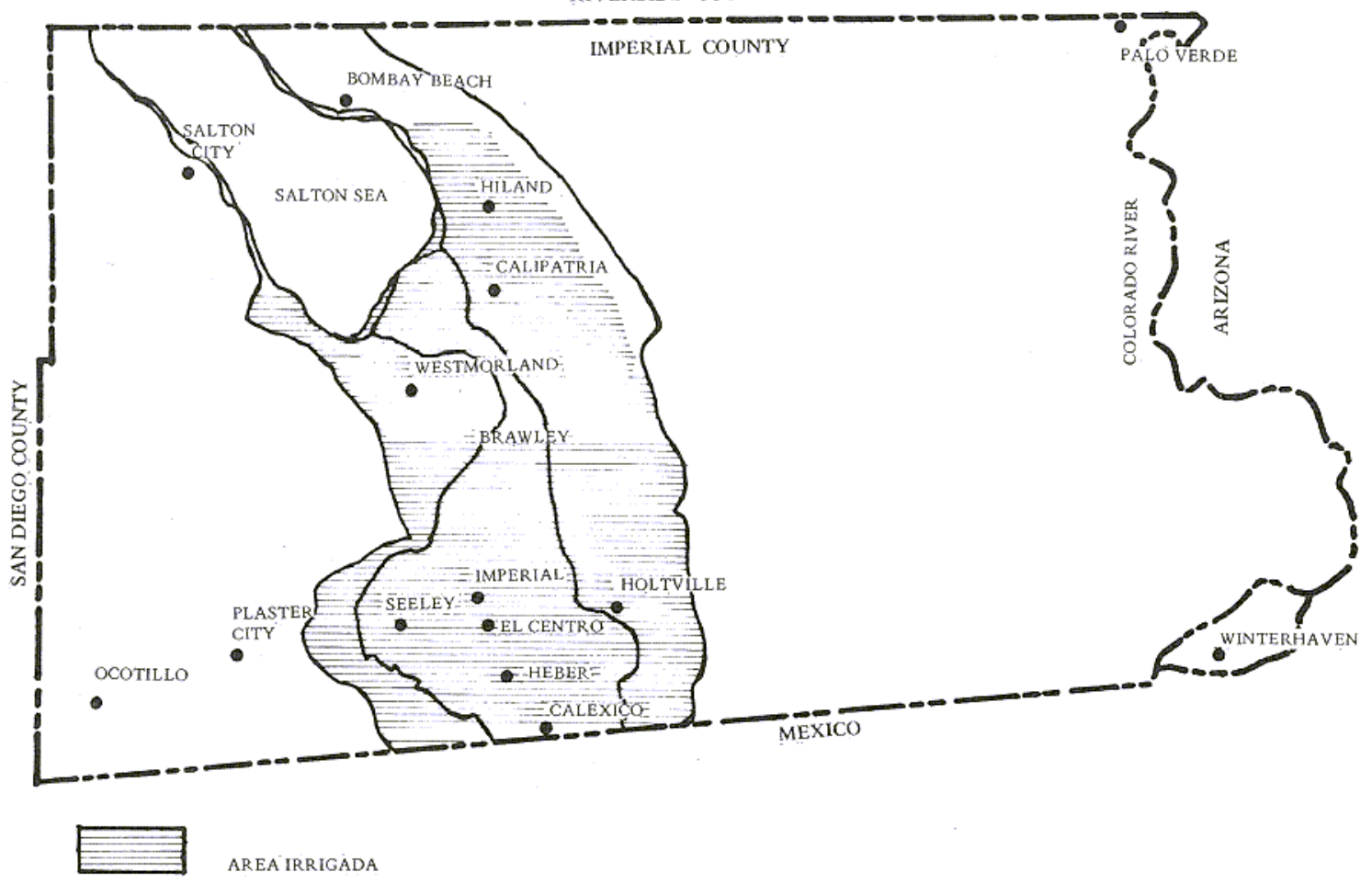


importante no sólo para los Estados Unidos, sino también significativa para México, especialmente en los presentes momentos de crisis que atraviesa el país.

Del reconocimiento de las consideraciones anteriores surgió una investigación que aborda este tema con el título de Fl Trabajador Agrícola Transmigrante de la Frontera Municipio de Mexicali-Condado de Imperial ${ }^{4}$.

Este artículo ofrece al lector una síntesis de dicho trabajo y de los hallazgos obtenidos del mismo.

Es pertinente destacar que la temática a que atiende el estudio, lo dota de un interés y mérito particulares, ya que por un lado aborda la práctica del transmigrante en su manifestación concreta y específica, presente en la frontera Mexicali-Imperial, donde existía un vacío de información sobre el fenómeno. $Y$ por otro, la presencia del transmigrante constituye uno de los rasgos más característicos que distinguen a la frontera norte de México del resto del país; cuyo conocimiento, a la vez que nos introduce en una dimensión poco explorada de la frontera, nos permite entender mejor la vida fronteriza. Aunado a lo anterior, los drásticos cambios experimentados en la economía de México, durante los dos últimos años, han contribuido a acentuar la importancia de este proyecto, por las implicaciones que afectan de manera especial a la frontera, donde los transmigrantes juegan un papel de primer orden, tanto para la economía fronteriza nortcamericana como para la nacional.

El estudio ha centrado la atención en los transmigrantes residentes de Mexicali y que realizan labores agrícolas en el Valle Imperial, Ca. La elección de este grupo obedece a que la agricultura es la actividad económica fundamental de la región y coincidentemente, de todos los transmigrantes que se localizan a lo largo de la frontera. Son los trabajadores agrícolas el grupo más numeroso y de mayor peso para las economías fronterizas, correspondiendo a la frontera Mexicali-Imperial una elevada concentración de transmigrantes agrícolas.

Para evaluar la importancia del transmigrante a lo largo de la frontera, cabe citar que el Departamento del Trabajo de los EE. UU. ha estimado que los transmigrantes representan entre el 25 y 30 por ciento del ingreso perci. bido por esta fuerza laboral en las comunidades fronterizas mexicanas ${ }^{5}$. En algunos casos se estima que los ingresos alcanzan el $35 \%$, y para Mexicali, se calcula que el $21 \%$ de los salarios corresponden a la fuerza de trabajo de los transmigrantes 6 .

4 Este proyecto formó parte del Programa de Investigación del Instituto de Investigaciones Sociales de la $\mathrm{UABC}$, en el período 1981-1983, y se realizó bajo convenio SEP-UABC.

$5 \mathrm{La}$ Broucherie, Roger, Aliens in the fields: The green card commuter under the Inmigration and Naturalization laws, Standford Law Review, 21, No. 6, 1969, Stand ford, Ca., p. 1762.

6 Fernández, Raúl. La fröntera México-Estados Inidos, Terra Nova, 1980, México, p. 136. 
importante no sólo para los Estados Unidos, sino también significativa para México, especialmente en los presentes momentos de crisis que atraviesa el país.

Del reconocimiento de las consideraciones anteriores surgió una investigación que aborda este tema con el título de Fl Trabajador Agrícola Transmigrante de la Frontera Municipio de Mexicali-Condado de Imperial ${ }^{4}$.

Este artículo ofrece al lector una síntesis de dicho trabajo y de los hallazgos obtenidos del mismo.

Es pertinente destacar que la temática a que atiende el estudio, lo dota de un interés y mérito particulares, ya que por un lado aborda la práctica del transmigrante en su manifestación concreta y específica, presente en la frontera Mexicali-Imperial, donde existía un vacío de información sobre el fenómeno. $Y$ por otro, la presencia del transmigrante constituye uno de los rasgos más característicos que distinguen a la frontera norte de México del resto del país; cuyo conocimiento, a la vez que nos introduce en una dimensión poco explorada de la frontera, nos permite entender mejor la vida fronteriza. Aunado a lo anterior, los drásticos cambios experimentados en la economía de México, durante los dos últimos años, han contribuido a acentuar la importancia de este proyecto, por las implicaciones que afectan de manera especial a la frontera, donde los transmigrantes juegan un papel de primer orden, tanto para la economía fronteriza norteamericana como para la nacional.

El estudio ha centrado la atención en los transmigrantes residentes de Mexicali y que realizan labores agrícolas en el Valle Imperial, Ca. La elección de este grupo obedece a que la agricultura es la actividad económica fundamental de la región y coincidentemente, de todos los transmigrantes que se localizan a lo largo de la frontera. Son los trabajadores agrícolas el grupo más numeroso y de mayor peso para las economías fronterizas, correspondiendo a la frontera Mexicali-Imperial una elevada concentración de transmigrantes agrícolas.

Para evaluar la importancia del transmigrante a lo largo de la frontera, cabe citar que el Departamento del Trabajo de los EE. UU. ha estimado que los transmigrantes representan entre el 25 y 30 por ciento del ingreso percibido por esta fuerza laboral en las comunidades fronterizas mexicanas 5 . En algunos casos se estima que los ingresos alcanzan el $35 \%$, y para Mexicali, se calcula que el $21 \%$ de los salarios corresponden a la fuerza de trabajo de los transmigrantes 6 .

\footnotetext{
4 Este proyecto formó parte del Programa de Investigación del Instituto de Investigaciones Sociales de la $\mathrm{UABC}$, en el período 1981-1983, y se realizó bajo convenio SEP-UABC.

$5 \mathrm{La}$ Broucherie, Roger, Aliens in the fields: The green card commuter under the Inmigration and Naturalization laws, Stand ford Law Review, 21, No. 6, 1969, Standford, Ca., P. 1762.

6 Fernández, Raúl. La fröntera México-Estados Inidos, Terra Nova, 1980, México, p. 136.
} 
En cuanto a la participación de esta fuerza de trabajo para el desarrollo agrícola del Valle Imperial, baste decir por el momento que el condado de Imperial se encuentra entre los 5 primeros condados del estado de California en producción agrícola, y que el $25 \%$ de la producción de hortalizas y legumbres de los Estados Unidos provienen de California ${ }^{7}$. Para que esto haya sido posible, ha debido intervenir en forma determinante la fuerza de trabajo extranjera en ese estado, y en el Valle Imperial difícilmente se habría alcanzado tal desarrollo sin la mano de obra transmigrante, que se estima en más del $85 \%$ del total de la fuerza del trabajo empleada en la agricultura.

Los objetivos que se fijaron en el proyecto, fueron los siguientes:

1) Elaborar un análisis histórico de la participación de la fuerza de trabajo extranjera, en el desarrollo agrícola del estado de California, ubicando en este contexto al trabajador agrícola transmigrante, en el marco de las relaciones capitalistas de producción.

2) Estudiar y describir el surgimiento y desarrollo agrícola capitalista del Valle Imperial, destacando la participación del transmigrante.

3) Analizar el surgimiento del transmigrante así como las características de su status legal, en los EE. UU.

4) Examinar las características del mercado laboral en que se emplea el transmigrante de esta frontera, y su importancia en el mismo.

5) Caracterizar al transmigrante agrícola de la frontera Mexicali-Imperial.

En cuanto a las hipótesis planteadas, figuran una central y dos particulares. En la primera se afirma: en la zona fronteriza sur de los EE.UU., concretamente en el condado de Imperial, existe un doble mercado de trabajo derivado de la presencia de trabajadores agrícolas transmigrantes, quienes constituyen la principal fuente de mano de obra para la agricultura de la región. Esta oferta externa de trabajo propicia una depresión en los niveles de salarios y condiciones de trabajo locales.

En relación a la historia laboral del transmigrante agrícola se plantea: la historia laboral del transmigrante agrícola del Valle Imperial, se caracteriza por una amplia experiencia en tareas agrícolas tanto en México como en EE. UU., y por una escasa participación dentro del mercado laboral no agrícola.

7 Hearings. The impact of commuter aliens along the Mexican and Canadian Borders Before the Select Commission on Western Hemisphere. Part II, San Diego, Ca., February 9-10, 1068, 156. 
Por último, proponemos que los transmigrantes agrícolas de esta frontcra presentan un bajo nivel de participación en los procesos político-sindicales en México. Sin embargo, con su incorporación a las relaciones de producción capitalista de la agricultura norteamericana, se inicia un proceso ascendente de participación y toma de conciencia sindicalista.

Es posible afirmar que una de las aportaciones más valiosas de este trabajo, ha sido la de sentar una base para la realización de futuras investigaciones sobre el tema. En ese sentido el Instituto de Investigaciones Sociales ha iniciado un análisis sobre la transnigración en la frontera Tijuana-San Diego, el cual permitirá un conocimiento más amplio y profundo sobre los transmigrantes, ya que el área en que se ubica el estudio cs eminentemente urbana, caracterizado por una base económica muy amplia, a diferencia de la frontera Mexicali-Imperial donde la agricultura es la base de la economía. Esto permite suponer variaciones importantes tanto en la génesis de los transmigrantes como en sus características y desarrollo.

La exposición de este artículo incluye el siguiente orden: 1) Consideraciones teóricas, 2) Origen y status legal del transmigrante, 3) Número, ocupación y efectos, 4) El mercado de trabajo, 5) Características del trabajador agrícola transmigrante en esta frontera, y 6) Conclusiones, que incluyen las perspectivas para este tipo de trabajador y recomendaciones ${ }^{8}$.

\section{CONSIDERACIONES TEORICAS *}

El surgimiento y desarrollo de la agricultura en el estado de California (EE.UU) se efectuó mediante la implantación de un modelo de distribución de la tierra, basado en lo fundamental, en grandes concentraciones de la propiedad y el establecimiento decisivo de una seric de medidas políticas y cconómicas, tales como las concesiones ferroviarias y la especulación de la tierra.

Sin embargo, dada la escasez de población existente en el estado y la consiguiente dificultad para abastecer la demanda de mano de obra, se determinó fomentar la inmigración de trabajadores del extranjero durante sucesivos períodos migratorios, lo cual dio como resultado la llegada de pobladores chinos, japoneses, filipinos, negros del sur de Estados Unidos y, finalmente, la migración más numcrosa, que corresponde a los trabajadores mexicanos.

\footnotetext{
8 Hemos omitido en este artículo recomendaciones metodológicas y de contenido, que sin embargo aparecen en el documento final de la investigación. El proyecto en marcha, Tijuana-San Diego, retoma estas consideraciones.

* Este apartado estuvo a cargo del Lic. Pablo Jesús González Reyes, quien también realizó el análisis de la información de la encuesta.
} 
La disponibilidad permanente de fuerza de trabajo, proveniente del extranjero, fue un factor determinante para que Estados Unidos lograra desarrollar las regiones agrícolas tanto de California como de todo el suroeste norteamericano, en donde la fuerza de trabajo mexicana ha desempeñado un papel de primera importancia.

Es por ello de trascendencia para este trabajo, ubicar en un contexto teórico las corrientes migratorias de trabajadores mexicanos hacia el país vecino, fenómeno que se ha venido manifestando de manera acuciante a lo largo del presente siglo.

En general, podemos afirmar que los flujos migratorios son resultado de los diferentes niveles de desarrollo existentes entre regiones y países. En el caso de la migración México-Estados Unidos, por un lado tenemos a un país en vías de desarrollo, mientras que por el otro se trata del país más desarrollado del mundo: La ley del desarrollo desigual y combinado nos ofrece una óptica para analizar y comprender los procesos migratorios.

La esencia de la ley del desarrollo señala que todo avance histórico se produce mediante el crecimiento más acelerado, o bien, más lento, de las fuerzas productivas en uno u otro segmento de la sociedad, debido a las diferencias presentes en las condiciones naturales y en las condiciones históricas. Estas desigualdades traen como consecuencia un carácter de expansión o comprensión en toda una época histórica e imparten distintas proporciones de crecimiento a los diferentes pueblos, en las diversas ramas de la economía, en las diferentes clases sociales, instituciones sociales y campos de cultura. Sin embargo, las variaciones existentes entre los múltiples factores de la historia sientan la base para el surgimiento de un desarrollo excepcional, en el cual las características de una etapa más baja del desarrollo social se mezclan con la de otra superior. Estas deformaciones combinadas poseen un carácter ampliamente contradictorio y exhiben marcadas peculiaridades. Esta es la csencia del desarrollo combinado ${ }^{9}$.

El desarrollo desigual, en la expresión del modo de producción capitalista, se deriva de la lógica del capital y de la división de trabajo que éste exige según los imperativos de la tasa de ganancias. Así tenemos que, históricamente. los avances en la capacidad productiva se han reflejado en el crecimiento y en el movimiento de las poblaciones humanas. El desarrollo de la capitalización ha estimulado el crecimiento continuo de la población y la migración constante tanto a nivel interno de los países, como a escala internacional. Es decir. la migración representa en este sentido una internacionalización de la fuerza de trabajo expresada en sus diversas modalidades, llámese inmigrantes legales, braceros, indocumentados o transmigrantes. En otras palabras, la migración representa un vínculo fundamental entre los mercados nacionales e internacionales, como reflejo de un grado relativo de interdependencia.

$9 \mathrm{Vid}$. Trotski, León et al. La ley del desarrollo desigual y combinado. 
La expulsión de la fuerza de un área territorial se debe principalmente, a las disparidades existentes entre los mercados laborales regionales y nacionales, dentro y fuera de distintos países. Donde los mercados se caracterizan por condiciones más o menos iguales, como son los casos de Canadá y Estados Unidos, Francia y Alemania Occidental, los incentivos para la migración son menores. Por el contrario, donde las condiciones de los mercados son muy diferentes en cuanto a disponibilidad de empleo y niveles salariales, como es el caso de México y Estados Unidos, los flujos migratorios adquieren proporciones mayores.

La migración México--Estados Unidos responde a los requerimientos internos de mano de obra del capital norteamericano, así como también a la estructura agrícola que la penetración capitalista ha producido en México. Un factor fundamental de este proceso de capitalización es la intervención de las empresas trasnacionales en la agricultura mexicana cuyo crecimiento es cada vez más definitivo. Así tenemos que de 1940 a 1970 el porcentaje del capital extranjero invertido en la agricultura avanzó del $7 \%$ al $60 \% 10$. Como consecuencia del creciente control de la producción por parte de los inversionistas norteamericanos, ha surgido un complejo proceso de descampesinización, donde los trabajadores se ven precisados a incorporarse a las explotaciones agroindustriales, cmigrar a la ciudad o a buscar empleo como jornaleros agrícolas en Estados Unidos.

A lo largo de este siglo, podemos identificar cuatro tipos de inmigrantes mexicanos en los Estados Unidos:

1) Los inmigrantes legales que fueron admitidos por las autoridades norteamericanas previo otorgamiento de la visa de inmigrantes.

2) Los transmigrantes, commuters o también llamados "tarjetas verdes".

3) Los braceros admitidos por las autoridades norteamericanas para desempeñar trabajos bajo contrato.

4) Los inmigrantes no documentados, llamados también "espaldas mojadas" o "alambristas" 11.

El fenómeno de la transmigración, como se ha señalado en la introducción, se refiere a la modalidad migratoria de los trabajadores transmigrantes o commuters, según la denominación norteamericana.

A continuación se muestran las proporciones de estos trabajadores que emigraron a Estados Unidos procedentes de México desde 1952 hasta 1968.

$10 \mathrm{Vid}$. Gómez, Manuel A. Las trasnacionales en la agricultura mexicana, p. 114.

11 Cf. Bustamante, Jorge A. Espaldas mojadas: Materia prima para la expansión del capital norteamericano, p. 15. 


\section{INMIGRANTES MEXICANOS ADMITIDOS COMO COMMUTERS A LOS ESTADOS UNIDOS}

\begin{tabular}{lrrrrr}
\hline Año & $\begin{array}{c}\text { Commuters } \\
\text { Admitidos }\end{array}$ & Año & $\begin{array}{c}\text { Commuters } \\
\text { Admitidos }\end{array}$ & Año & $\begin{array}{c}\text { Commuters } \\
\text { Admitidos }\end{array}$ \\
1952 & 9,079 & 1958 & 26,791 & 1964 & 34,448 \\
1953 & 17,183 & 1959 & 22,909 & 1965 & 40,686 \\
1954 & 30,645 & 1960 & 32,708 & 1966 & 47,217 \\
1955 & 43,702 & 1961 & 41,476 & 1967 & 43,034 \\
1956 & 61,320 & 1962 & 55,805 & 1968 & 44,000 \\
1957 & 49,321 & 1963 & 55,986 & & \\
\hline
\end{tabular}

FUENTE: Select Commission on Western Hemisphere Inmigration, pp. 40-56.12

Como se puede apreciar en este cuadro, en un período de 17 años emigraron en calidad de transmigrantes o commuters a los Estados Unidos 656,310 trabajadores mexicanos.

Los trabajadores agrícolas transmigrantes que comprenden nuestro ámbito de estudio, surgen como resultado de los requerimientos de mano de obra por parte de los empresarios norteamericanos en los campos agrícolas del Valle Imperial, zona ampliamente reconocida por la riqueza de su producción agrícola. La disponibilidad de fuerza de trabajo mexicana y su permanente reproducción han permitido el desarrollo agrícola de esa región, como veremos más adelante.

\section{ORIGENES Y STATUS LEGAL DEL TRANSMIGRANTE.}

El fenómeno de la transmigración México-Estados Unidos, no es reciente ni exclusivo de la misma. Surge con la delimitación de ambas fronteras y ocurre también entre otros países. 13

Los antecedentes inmediatos de esta forma de migración entre México y EE.UU., se encuentran en la terminación, en 1964, de la Ley Pública 78, mejor conocida como Programa de Braceros, que permitió la importación de trabajo mexicano para realizar tareas agrícolas en aquel país. Muchos de los trabajadores incorporados al mencionado programa, una vez concluido, continuaron con su patrón de empleo ahora en calidad de transmigrantes. ${ }^{14}$

12 Ibid. p. 28.

13 Véase: Murillo Gabriel, Theory and Methodology in the study of international Labor Migration and Urban Informal Sector of Colombia, Bogotá, Universidad de los Andes, Bogotá, Colombia, 1981, y Tuppen, J.N.: A Geographical Appraisal fo Transfrontier Commiting in Western Europe. The example of Alsace, en: International Migration Review, Vol. 12, No. 23, otoño de 1978.

14 North, Davis y Houston, Marion. The characteristics and role of Ilegal Aliens in the U.S. Labor Market: An exploratory study. Linton \& Company, 1976. Washington, D. C. p. A-24. 
En el caso de la frontera Mexicali-Imperial, los orígenes más remotos del transmigrante se localizan en la etapa de formación de sus respectivos valles. El surgimiento agrícola de la región presentó características que propiciaron la práctica del transmigrante. Mientras que en el Valle Imperial, la tierra fue objeto de explotación individual y con una gran diversificación de cultivos, 15 en el Valle de Mexicali existió por espacio de 30 años el control monopólico de la Colorado River Land Company, la cual excluyó sistemáticamente a los trabajadores mexicanos prefiriendo en su lugar a extranjeros de orígen asiático. ${ }^{16}$ Los mexicanos que llegaban del sur de Baja California o del centro del país, "si tenían suerte, se hacían peones de agricultores extranjeros o pasaban como braceros al Valle Imperial". 17

Con lo anterior definimos brevemente los antecedentes de los transmigrantes como fuerza de trabajo esencial para la agricultura norteamericana. En cuanto a los orígenes legales de los transmigrantes se requiere de un examen aparte.

Originalmente considerados sólo como "visitantes de negocios", los transmigrantes adquirieron el status de inmigrantes en los Estados Unidos como un esfuerzo del gobierno para prevenir que los extranjeros europeos sobrepasaran la cuota legal de inmigración.

Antes de 1921 no existían restricciones al número de inmigrantes extranjeros en los EE.UU. En ese año, el Congreso estableció restricciones temporales a la inmigración de extranjeros que fueron aplicadas solamente a los países del hemisferio Este. La siguicnte revisión de las leyes ocurrió en 1924, año en que se estableció un sistema permanente de cuotas de selección y control. El acta declaraba que los nativos del hemisferio Occidental debían obtener visas de inmigración para entrar a los EE.UU. aún cuando no estuvieran sujetos a cuota. Los transmigrantes fueron considerados entonces como visitantes y eran libres de continuar cruzando a trabajar al vecino país. ${ }^{18}$

Sin embargo, en 1927, las autoridades de inmigración reconsideraron su posición y declararon que cualquier extranjero que ingresa a los EE.UU., sería considerado como inmigrante, y debía obtener una visa para tal finalidad. Esto incluía implícitamente a los transmigrantes. A pesar de que esta situación fue objetada en las Cortes, en 1919 la Corte aprobó la nueva interpretación de la ley. 19

\footnotetext{
15 Véase: Henderson, Tracey, Imperial Valley, T. I. Nereyech Printers Inc., 1968, San Diego, Ca.

16 Estrella, Gabriel. El origen de la región de los valles de Mexicali e Imperial, desde la perspectiva de las relaciones sociales. Cuadernos de Ciencias Sociales. No. 1, IIS, UABC, Mexicali, p, 192.

17 Diesbach, Nicole. El proceso de producción agrícola en el valle de Mexicali. Tesis de licenciatura, Escuela de C. Soc. y Políticas, UABC, Mexicali, 1977 pp. 55-56.

18 Audiencias, Parte II, op. cit. p. 2.

19 Idem.
} 
Por ese tiempo, las autoridades de inmigración concluyeron que el Congreso no deseaba interferir con el patrón establecido de transmigrantes regulares. Dadas las dificultades que implicaba la obtención de una nueva visa para cada entrada, las autoridades de inmigración idearon una tarjeta de identificación para extranjeros que cruzaban frecuentemente la frontera. La expedición de estas tarjetas fue aprobada por el Congreso en el Acta de Registro de 1940.20

De esta forma el transmigrante podía obtener una tarjeta de identificación, misma que le daba derecho a trabajar. Este arreglo estaba en armonía con la política del "buen vecino" y evitaba transtornos en el área fronteriza. De este modo la interpretación de las leyes creó las bases para el desarrollo del sistema de transmigrantes.

A partir de lo anterior, el transmigrante o commuter, como lo designa el Immigration and Naturalization Service (Servicio de Inmigración y Naturalización, SIN), de los EE.UU., es definido como aquel extranjero residente de las zonas fronterizas mexicana o canadiense que posee la forma $\mathrm{I}-151$, que le concede el status de residente permanente de los Estados Unidos, pero que ha decidido hacer uso de una práctica por mucho tiempo aceptada entre los tres países (EE.UU., México y Canadá), de vivir fuera de Estados Unidos y trabajar en él. Como de hecho estos inmigrantes no residen en el país, a diferencia de otros poseedores de la forma $1-151$, su tarjeta es perforada con anillo metálico y adjuntada la forma $1-178$, donde se indica su lugar de empleo y la cual debe ser renovada cada seis meses. 21

Sin embargo debe ser aclarado que la acción de perforar la tarjeta del transmigrante, no implica un reconocimiento oficial al status migratorio de este tipo de trabajadores. En ese sentido, el programa de commuters o transmigrantes está considerado como una aplicación administrativa de la legislación norteamericana para las fronteras de México y Canadá. Es un tipo de arreglo único cuyo carácter se describe a continuación:

"La situación del commuter no encaja en ninguna categoría precisa de los Estatutos de Inmigración. Su status es uno artificial y realizado sobre la base de relaciones internacionales mantenidas y apreciadas entre vecinos amistosos". 22

Parece ocioso señalar que la "flexibilidad" del gobierno de EE.UU. al aceptar esta medida administrativa del Servicio de Inmigración y Naturalización, apoya el interés expansionista del capital norteamericano, al permitirle operar con un mercado de trabajo internacional y consecuentemente con un ejército de reserva que le ofrece grandes ventajas tales como el ahorro de los costos de producción de esta fuerza de trabajo.

\footnotetext{
20 Idem.

21 North \& Houston, op. cit., A-1.

22 Audiencias, Parte II, op. cit., p. 3
} 
Conviene señalar que existen tres categorías de commuters o transmigrantes, según clasificación del SIN. Los ciudadanos (norteamericanos) commuters, los commuters no-inmigrantes, y los commuters tarjeta-verde ${ }^{23}$, mismos a los que se enfocó nuestro estudio. De las tres categorías mencionadas, es la de los commuters tarjeta-verde la más importante, tanto en número como en participación en las economías fronterizas norteamericanas.

También debe anotarse que estos trabajadores tienen la opción de trasladarse a radicar en los EE.UU. y si así lo hicieran tienen garantizados todos los derechos de cualquier extranjero con residencia permanente en el país, incluyendo el derecho de convertirse en ciudadanos norteamericanos. Sin embargo, los green-card commuters por definición han decidido no ejercer este derecho. 24

Otra característica de los transmigrantes portadores de la forma I-151 es que rehusan ser clasificados como commuters por las autoridades del SIN, ya que esto implica una serie de desventajas que consisten en:

1) Mientras que el tarjeta-verde mantenga su residencia fuera del país, no puede solicitar la ciudadanía norteamericana.

2) El commuter no puede emigrar a su familia hacia los EE.UU. mientras no resida en el país.

3) La falta de empleo por un período mayor a los 6 meses, provoca que las autoridades consideren que el commuter ha abandonado su status de inmigrante -aún cuando haya entrado en el país varias veces por motivos diferentes a los del trabajo-, y le retiren su tarjeta migratoria. 25

4) Finalmente existe la posibilidad de que si el Departamento del Trabajo certifica que en un determinado negocio existe una disputa laboral, el transmigrante no puede aceptar empleo en tal lugar hasta que se concluya el problema. 26

Durante muchos años el sistema de transmigrantes no ofreció ningún problema a las autoridades de los EE.UU. Sin embargo, en 1867, durante las discusiones de la Comisión Selecta sobre Inmigración del Hcmisferio Occi-

23 En la primera categoría se incluye a ciudadanos norteamericanos, que residen fuera de EE.UU. y cruzan a trabajar a su país. Los segundos son extranjeros con un permiso de trabajo, pero que no han adquirido el status de residentes permanentes de los EE.UU., se encuentran principalmente en el estado de Texas.

24 North y Houston, op. cit., A-1.

25 Esta situación revela que realmente la tarjeta del commuter no es más que un permiso de trabajo. No obstante la falta de empleo por un motivo justificado deja sin efecto la disposición señalada.

26 North \& Houston, op. cit., A-1. 
dental, y en 1968, en las audiencias ante la citada comisión 27 , se puso en evidencia que existía una controversia sobre el programa de transmigrantes.

A continuación se exponen de manera suscinta los principales argumentos esgrimidos tanto en favor como en contra del sistema de transmigrantes, por los distintos grupos y sectores sociales de los EE.UU.

En primer término, quienes se oponen a la continuación de la práctica del transmigrante señalan que:

1) Provocan desempleo en las comunidades fronterizas de los EE.UU.

2) Deprimen el nivel de salarios en estas zonas.

3) Propician un deterioro en las condiciones de trabajo de la región donde se concentran.

4) Compiten en forma ventajosa con los trabajadores nacionales, desplazando especialmente a los minorías mexico-americanas.

5) Drenan la economía de los EE.UU. por la fuga de divisas que se realiza a través de ellos hacia México.

6) Obstaculizan las posibilidades de sindicalización en el campo y son utilizados como esquiroles.

7) Los únicos que se benefician con su presencia son los patrones.

8) Su cancelación es necesaria, beneficia a los EE.UU. lo mismo que a México, al evitarle "la molestia" de este tipo de migrantes.

Por su parte los grupos que se pronuncian a favor del sistema de transmigrantes argumentan que:

1) El commuter realiza trabajo que los ciudadanos norteamericanos en general no desean, por tanto, no compiten ventajosamente con los trabajadores domésticos.

2) Perciben el salario mínimo según la zona; en consecuencia, no deprimen el nivel de salarios.

27 Durante la reunión, en 1967, de dicha comisión, se puso de manifiesto que uno de los puntos involucrados en la política migratoria de los EE.UU. era el de los transmigrantes. La comisión solicitó al Departamento de Trabajo y Justicia, que preparara declaraciones explicativas sobre la situación del commuter. No obstante la gran publicidad que se le dio al asunto, se concluyó que no existía un cabal entendimiento del problema y de los efectos de una cancelación. Por tanto se organizaron audiencias públicas a las que asistiendo representantes de diferentes sectores, para dar su opinión sobre el sistema de transmigrantes y sobre la Propuesta 2790. introducida por el senador Kennedy encaminada a la restricción de ese programa. Las audiencias se llevaron a cabo en varias ciudades fronterizas principalmente durante 1968. 
3) Pagan impuestos y cumplen con la ley.

4) No demandan una serie de servicios a los que tienen derecho: (vivienda, educación, servicios públicos, asistencia social, etc).

5) Gastan la mayor parte de su salario en los EE.UU.

6) Las industrias relacionadas con la agricultura dependen casi exclusivamente de estos trabajadores.

7) Son de gran apoyo a las economías de la zona fronteriza.

8) Cualquier restricción al libre flujo de commuters afectaría a cientos de familias que dependen de este ingreso, lo mismo que a las relaciones de EE.UU. con México y Canadá.

Al final de las audiencias, dos miembros de la Comisión Selecta, Richard Scammon y Stanley Ruttenberg, presentaron un plan de restricciones al sistema de transmigrantes conocida como Propuesta Ruttenberg-Scammon, diferente de la Propuesta Kennedy, a la que se sumó una tercera promovida por la American Federation of Labor, llamada del Salario Mínimo.28 Sin embargo, el hecho de que ninguna acción ha sido tomada al respecto desde entonces a la fecha, prueba que el sistema de transmigrantes favorece los intereses de grupos muy poderosos y que éstos están bien representados en las esferas de decisión del gobierno norteamericano.

Efectivamente, la importancia del transmigrante para la economía fronteriza del sur de los EE.UU., puede ser evaluada a través del análisis de este grupo en cuanto a número, ocupacion y efectos; aspectos que se exponen a continuación.

\section{NUMERO, OCUPACION Y EFECTOS DEL TRANSMIGRANTE.}

Dado que la práctica del transmigrante o commuter tarjeta verde es una creación del Servicio de Inmigración y Naturalización de los Estados Unidos, y que no aparece como tal en ninguna agencia norteamericana o extranjera, sólo disponemos de los datos registrados por dicha oficina, con los reservas necesarias sobre su número y distribución. A esto hay que agregar que el SIN no cuenta con un registro estad ístico del número de transmigrantes que trabajan en los EE.UU. y que el tarjeta verde trata de ocultar su condición de transmigrante por las desventajas arriba citadas. A partir de los años sesenta se inicia una serie de conteos por muestreo en forma más o menos regular.

28 Véase, Roger La Broucherie, op. cit. 
En 1963 se realizaron dos de éstos (8 y 17 de mayo), donde se incluyó sólo a los portadores de la forma I-151. Los resultados: 33,867 y 34,224 respectivamente. Texas concentró ese año el 49 \% de los transmigrantes mientras que california el $38 \%$. En 1966, el conteo incluyó tanto a transmigrantes tarjeta verde como a los ciudadanos, sumando un total de 61,946, de los que 43,687 fueron mexicanos. El resto de los años, a partir de 1967, se contabilizó solamente a los tarjeta verde, año en que también se inicia la acción de perforar las tarjetas de los commuters. La última cifra disponible data de 1975 , y en ella la oficina del SIN marca 60,536 transmigrantes para las dos fronteras (mexicana y canadiense). De éstos, 51,922 corresponden a México. De todos los puertos de entrada, los que han concentrado el mayor número de transmigrantes han sido: San Ysidro, El Paso y Calexico 29 (ver cuadro I). No obstante la cifra de 60,536 registrada por el SIN, los autores North y Houston la refutan, y afirman que en base a sus estimaciones de ese año, existen 75,000 transmigrantes para las dos fronteras de EE.UU.30

Respecto al volumen de transmigrantes en la frontera Mexicali-Calexico, resulta difícil precisar, pues varía notablemente según la fuente consultada. El SIN registra para el año de 1982, 7,043 transmigrantes, en base a estimaciones. Sin embargo, informantes consultados de la propia oficina revelan que tal cifra no corresponde a la realidad y que el número oscila posiblemente entre los 15 y 18 mil. En ese sentido nuestras observaciones, durante las madrugadas en que se aplicaron las encuestas, nos indican que estas cifras son las más aproximadas a la realidad.

A pesar de que se estima que el número de transmigrantes constituyen un décimo del 1 o/o de la fuerza de trabajo de los Estados Unidos ${ }^{31}$, su importancia no debe situarse en relación a este porcentaje, sino en la significación del trabajo que desempeñan y su repercusión para las economías a ambos lados de la frontera.

En ese sentido, el Servicio de Inmigración y Naturalización realizó en 1967 por primera vez, una clasificación de transmigrantes por ocupación, que incluye 5 categorías: agricultura, industria, comercio, construcción, servicios y trabajo doméstico (en 1975 se agregó una sexta para "otros")*.

El cuadro II muestra los datos en números absolutos por puerto de entrada para ese año, en que del total de transmigrantes mexicanos 16,813 se emplearon en la agricultura o sea el 41.5 o/o. Destaca aquí la ciudad de Calexico que concentró el 40.7 o del total de los transmigrantes empleados en agri-

29 Los datos de 63 a 69 fueron obtenidos del Report of the Select Commission on Western Hemisphere Inmigration. Washington, D. C., Government Printing Office, 1968. Los datos de 1975, fueron publicados por North \& Houston op. cit., p. A-10, pero obtenidos del Servicio de Inmigración y Naturalización.

30 North \& Houston, op. cit., p. A-8.

31 La Broucherie, op. cit., p. 1762.

* Aunque dicha clasificación no precisa el tipo de trabajo que desempeñaban sino sólo los sectores, es reveladora de la actividad en que, con más frecuencia, se encuentra al transmigrante. 


\section{CUADRO I. TRABAJADORES TRANSMIGRANTES EN LA FRONTERA MEXICO-ESTADOS UNIDOS \\ $(1963,1966,1967,1969,1975)$}

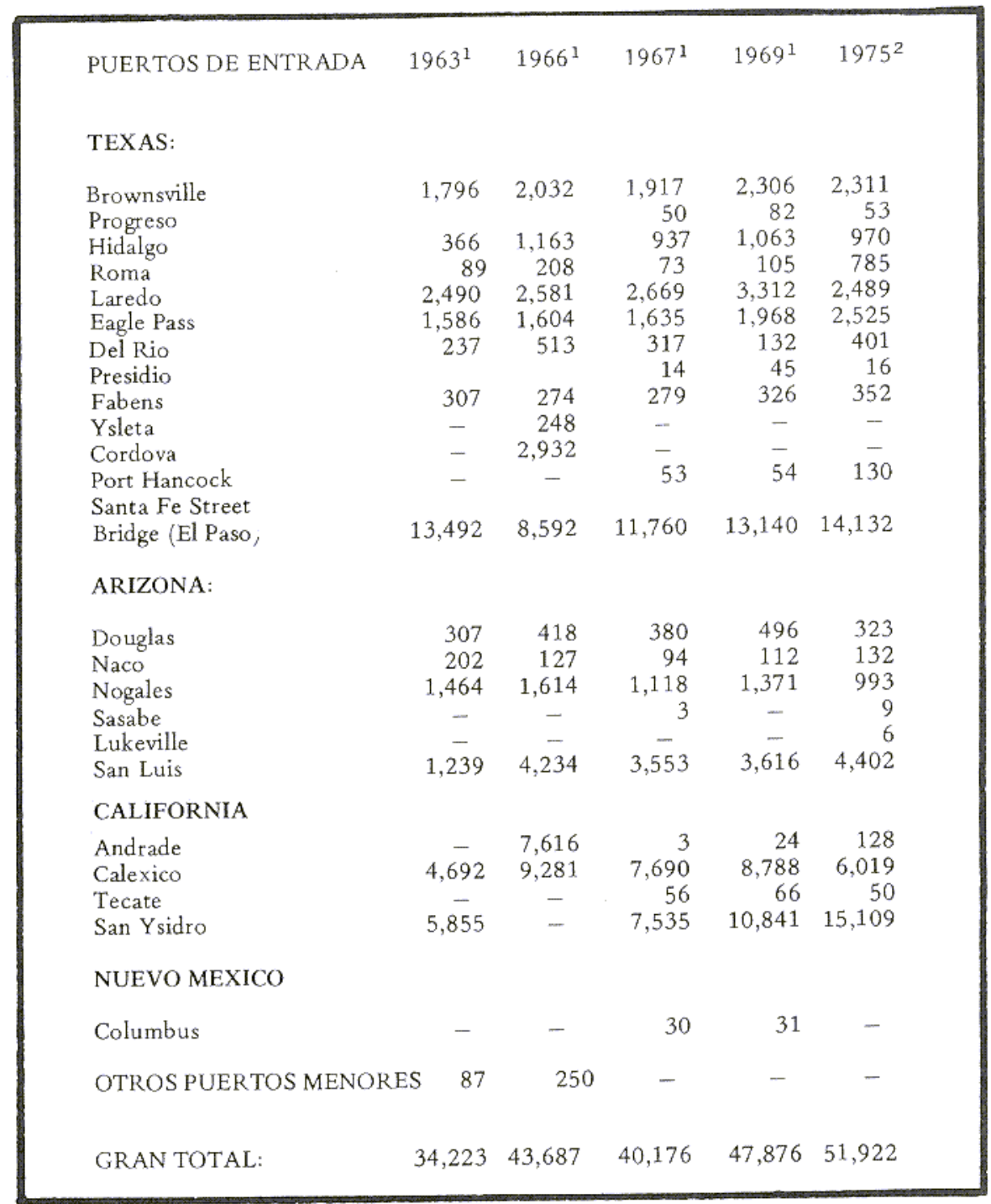

FUENTE 1: Report of the Select Commission on Western Hemisphere Inmigration, Washington, D. C., Government Printing Office.

FUENTE 2: DAVIS S. North \& Marion P. Houston, The Characteristics and Role of Illegal Aliens in the U. S. Labor Market: An Exploratory Study. Washington, Linton \& Company, 1976, p. A-10., p. A-10. 
CUADRO II. TRANSMIGRANTES REGISTRADOS POR SECTOR OCUPACIONAL* (1-30 de diciembre de 1967)

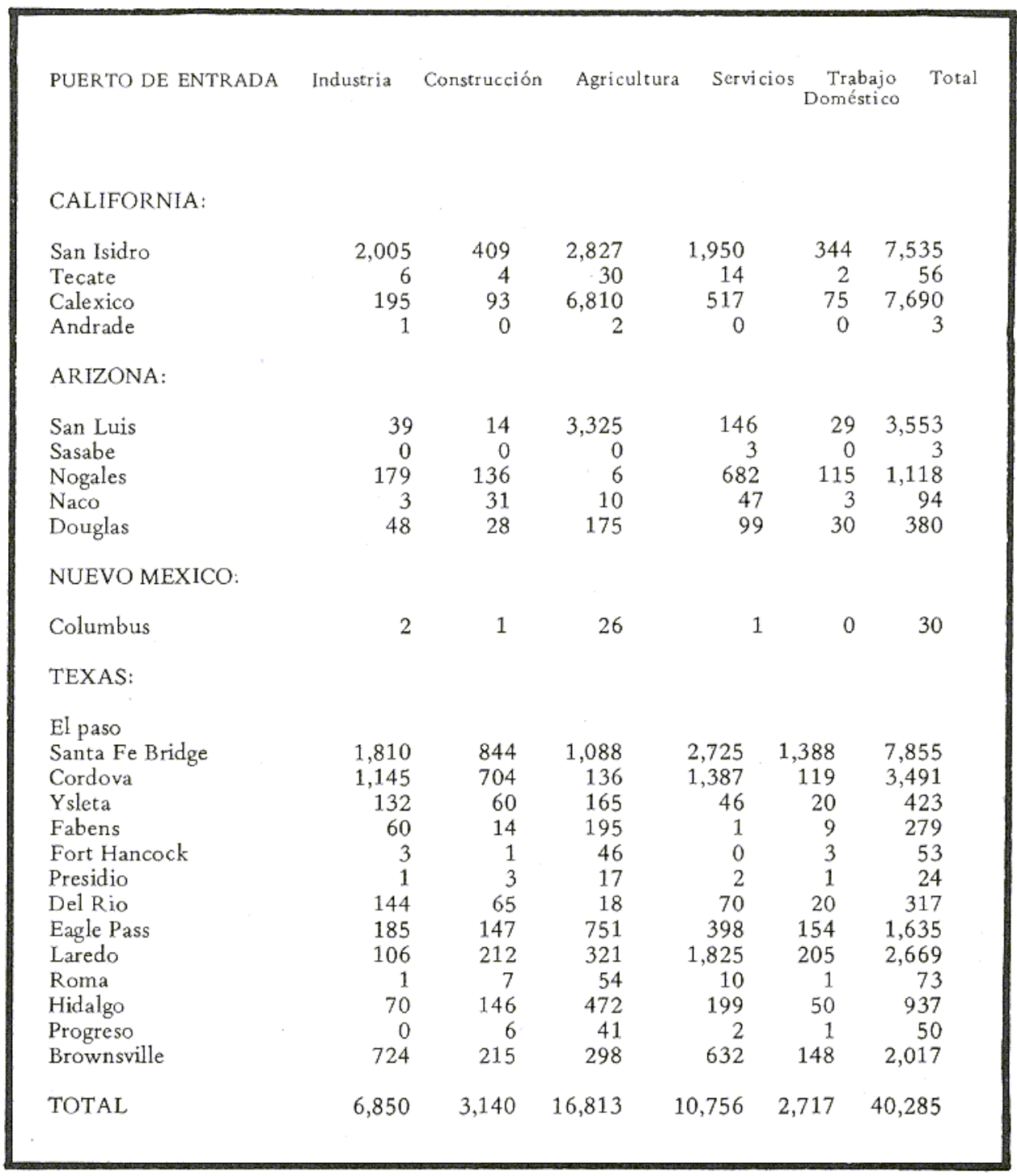

* Se incluye únicamente a transmigrantes portadores de la forma migratoria I-151.

FUENTE: Report of the select Commission of Western Hemisphere Inmigration, Washington, D. C.: Government Printing Office, 1968. 
cultura. Por otro lado del total de transmigrantes registrados ese año en la frontera Mexicali-Calexico, 6,810 se emplearon en labores agrícolas, esto representa el 88.5 o del total.32

Estos datos reflejan la importancia de la participación del transmigrante en la actividad agrícola de la región.

El cuadro III registra la distribución porcentual de transmigrantes por ocupación para 1975. Ese año el 37 o de transmigrantes se empleó cn la agricultura.

A diferencia de los transmigrantes de la frontera canadiense, quienes se emplean con más frecuencia en la manufactura, finanzas, seguros y bienes raíces, los mexicanos presentan una clara tendencia a emplearse en actividades agrícolas. (Ello obedece a las habilidades de los transmigrantes mexicanos y a la predominancia de zonas agrícolas en la frontera sur de los EE.UU.) 33

En relación al condado de Imperial, es posible afirmar que la ocupación de los transmigrantes es fundamentalmente la agricultura. En el Cuadro IV se observa que para los años de $1976,78,80$ y 82 , entre el 88.6 y el 90.4 \% de los transmigrantes se empleaba en actividades agrícolas.

La importancia del transmigrante también es significativa en relación al total de la fuerza de trabajo empleada en el Condado de Imperial. En 1967, los transmigrantes representaban el 28 o/o. 34

A decir del comisionado agrícola del Condado de Imperial: "Los commuters son indispensables para la actividad agrícola del valle, no podríamos operar sin ellos, y no creo que pudiéramos sustituirlos con trabajadores residentes del condado. A pesar de que nuestro índice de desempleo es bastante elevado, estas personas no están dispuestas a trabajar en labores agrícolas, no son aptas para este tipo de tareas". 35

Entre los efectos que han sido atribuidos a la presencia del transmigrante en las franjas de la frontera sur de los EE.UU. se ha logrado probar que los niveles salariales son menores que en el resto de los estados y del país en general y que registran mayores tasas de desempleo. En este sentido se afirma que el ingreso per cápita en estas zonas es de menos de la mitad que el promedio anual per cápita en EE.UU. y que existe un alto índice de pobreza.36

\footnotetext{
32 Report of the Select Commission. . op. cit.

33 North \& Houston, op. cit., A-23.

34 Stanley Knebel, Restrictive Admmission Standards: Probable Impact on Mexican alien commuter en Farm Labor Development, Washington, D.C., U.S. Dept. of Labor, Nov. 1968, p. 20.

35 Entrevista con Claude Finnell, Comisionado Agrícola del Condado de Imperial, Ca. El Centro, 1982.

36 North \& Houston, op. cit., A-38.
} 
CUADRO III. DISTRIBUCION DE COMMUTERS TARJETA VERDE POR OCUPACION, $1975^{*}$

\begin{tabular}{|lc|}
\hline \multicolumn{1}{|c|}{ ACTIVIDAD } & FRONTERA MEXICANA \\
(Clasificación del SIN) & \% DE COMMUTERS \\
& (Registrados por el SIN) \\
Industria & 24.3 \\
Construcción & 11.0 \\
Agricultura & 37.0 \\
Comercio y Servicios & 20.3 \\
Trabajo Doméstico & 4.0 \\
Otra & 3.1 \\
Total & $100 \%$ \\
Números Absolutos & 51,922 \\
\hline
\end{tabular}

* North, D. y Houston M., Op. cit. Los datos del cuadro fueron obtenidos del Servicio de Inmigración y Naturalización, pero publicados por North y Houston.

\section{CUADRO IV. NUMERO DE TRANSMIGRANTES POR ACTIVIDAD FRONTERA MEXICALI, B.C. - CALEXICO, CA.}

\begin{tabular}{|c|c|c|c|c|c|c|c|c|}
\hline \multirow[b]{2}{*}{ ACTIVIDAD } & \multicolumn{6}{|c|}{ AÑOS SELECCIONADOS } & & \\
\hline & \multicolumn{2}{|c|}{$\begin{array}{c}\text { ENERO } \\
1976\end{array}$} & \multicolumn{2}{|c|}{$\begin{array}{c}\text { ENERO } \\
1978\end{array}$} & \multicolumn{2}{|c|}{$\begin{array}{c}\text { ENERO } \\
1980\end{array}$} & \multicolumn{2}{|c|}{$\begin{array}{c}\text { ENERO } \\
1982\end{array}$} \\
\hline Industria & 160 & 2.8 & 190 & 3.1 & 229 & 3.3 & 229 & 3.2 \\
\hline Construcción & 40 & .7 & 38 & .6 & 47 & .7 & 53 & .8 \\
\hline $\begin{array}{l}\text { Agricultura } \\
\text { Comercio y }\end{array}$ & 5,103 & 90.4 & 5,419 & 89.3 & 6,141 & 88.8 & 6,240 & 88.6 \\
\hline Servicios & 260 & 4.5 & 325 & 5.4 & 395 & 5.7 & 416 & 5.9 \\
\hline Trabajo & & & & . & & & & \\
\hline Doméstico & 44 & .8 & 50 & .8 & 57 & .8 & 63 & .9 \\
\hline Otros & 39 & .7 & 44 & .7 & 44 & .6 & 42 & .6 \\
\hline Total & 5,646 & & 6,066 & & 6,913 & & 7,043 & \\
\hline
\end{tabular}

Inmigration and Naturalization Service, Report of the Permanent ResidentAlien Commuter and Seasonal Worker. (Archivo) Calexico, California. 
En el mismo orden de ideas, el Departamento del Trabajo, afirma que los condados fronterizos del sur de Estados Unidos, representan el $8.2 \%$ de la población de sus estados fronterizos y sin embargo, tiene el $13.9 \%$ o de las violaciones al Acta de Normas Justas de Trabajo, así como el $16.1 \mathrm{o} / \mathrm{o}$ de la cantidad de tiempos extra no pagados. ${ }^{37}$

Se ha encontrado también, que las firmas que emplean solamente residentes americanos pagan más frecuentemente los salarios establecidos por el citado documento, y que en cambio, entre aquellas que contratan commuters la excepción es que paguen los salarios establecidos. En general las primeras pagan salarios más altos que las que emplean commuters El Departamento del Trabajo tiene evidencia de que los residentes de EE.UU. desempleados, calificados para el empleo, afirman que no trabajarán por los salarios que actualmente pagan a los commuters. 38

La situación descrita ha conducido a pensar a los estudiosos del fenómeno que los commuters o transmigrantes constituyen en las zonas fronterizas un número significativamente importante para convertirse en un factor agravante de la desfavorable situación que prevalece en las ciudades fronterizas norteamericanas.

Por otro lado, los datos aquí presentados han sido de gran apoyo para la hipótesis planteada en la investigación. Estos datos, aunados a los resultados de la encuesta, avalan la afirmación de la existencia de un doble mercado de trabajo en el condado de Imperial, constituido por los transmigrantes, lo cual provoca que se generen las condiciones antes descritas. Estos aspectos serán examinados más a fondo en su oportunidad.

Finalmente, para entender la situación y comportamiento del commuter es necesario tener en cuenta que a pesar de que este trabajador tiene los derechos de todo residente de los EE.UU., rara vez actúa como si los tuviera: "ser un commuter tarjeta verde en el suroeste, es ser sujeto de sentimientos de profunda inseguridad. Tal vez, piensa el commuter, el gobierno norteamericano me quite mi tarjeta o cambie todo el sistema, tal vez afiliarme a un sindicato, o pedir un aumento acreciente el riesgo, para qué exponerme. ${ }^{39}$

\section{EL. MERCADO DE TRABAJO DEL TR ANSMIGRANTE EN LA FRONTERA MEXICALI-IMPERIAI}

El condado de Imperial se localiza con el extremo sureste del estado de California, Estados Unidos de América, en tierras que colindan por el Sur con el estado de Baja California, México, por el Este con el Río Colora-

$37 \mathrm{Ibid}$. p. A-39.

38 La Broucherie, R. op. cit., 1765.

39 North \& Houston, op. cit., pp. A-3 y A-4. 
do, por el Norte con el condado de Riverside, Ca. y por el Oeste con el condado de San Diego, Ca. Abarca una superficie de 4,597 millas cuadradas, (ver mapa), y tiene una población de $92,100 \mathrm{hbts.} 40$

El poblamiento de la región fue posible gracias a la irrigación de estas tierras con aguas del Río Colorado, constituyéndose desde sus inicios, en una región eminentemente agrícola. Formalmente esta actividad se inició en 1901, cuando se realizó la primera derivación de agua, permitiendo el cultivo de 1,500 acres. 41

El desarrollo agrícola, exigía asegurar el suministro de agua. En este sentido tres acciones estuvieron encaminadas a lograr este objetivo: la formación del distrito de riego (1911) el cual abarca 1,000 millas; el proyecto Boulder Canyon, aprobado en 1928 y la construcción del canal Todo Americano, orgullo de la tecnología norteamericana y base de la agricultura del valle, se inició en 1934 y se concluyó en 1942.42

Aunque los primeros pobladores llegaron con el propósito de formar pequeñas empresas o mas bien pequeñas granjas, lo cierto es que una vez iniciada la irrigación, se habrían de modificar las condiciones iniciales para sentar las bases de una agricultura en gran escala. "El capitalismo corporativo, en su más amplio sentido, fue la fuerza que condujo al país a la conversión de miles de acres de tierras públicas en propiedad privada. . a través de una integración tecnológica, financiera y de mercado se redujo a las granjas familiares a un dulce recuerdo". 43

Ahora bien, un elemento indispensable para el desarrollo de la agricultura comercial es la disponibilidad de mano de obra. De este modo, la utilización de fuerza de trabajo mexicana ocurrió desde los primeros tiempos aunque en forma y proporciones distint as a las actuales.

La penctración de capital en la agricultura creó un tipo de mercado de trabajo cuyo concepto central era la reserva de mano de obra. Esta debía ser ocasional y lateral al proceso de producción. La conexión real entre la mano de obra y el agricultor debía durar sólo el tiempo necesario para cosechar el cultivo, cualquiera que este fuese.

Los requerimientos variaban en función de la etapa en que se encontrara el cultivo, sin embargo "en aquellos condados donde se encontrara a una agricultura en gran escala, una producción diversificada, departamentos de

40 Annual Planning Information, 1982, p. 2.

41 Henderson Tracey, op. cit., p. 3.

42 Imperial Irrigation District, 1980, p. 4.

43 Galarza, Enesto, Farm Workers and Agribussiness in California, 1947-1960 University of Notre Dame Press, 1977, London, p. 3. 
trabajo bien organizados, los braceros se transformaron en la fuente básica de mano de obra, de una amplia gama de actividades. Este era el caso de Imperial, San Diego, Riverside, Ventura y Monterrey."4 4

De esta forma para 1958, en el condado de Imperial se contrataron 12,702 trabajadores temporales, de ellos 12,050 eran mexicanos. Esta situación de predominancia de los braceros en todos los cultivos de importancia en el condado, alcanzaban desde 1957 la proporción de 70 \% de trabajadores estacionales. 45

Actualmente, los períodos en que los requerimientos de mano de obra son más intensos en el valle, van de noviembre a enero y de abril a junio, mientras que durante el Programa de Braceros su empleo se prolongaba todo el año.

Tenencia de la tierra y producción agrícola.

Durante muchos años, el tamaño de los ranchos del valle fue más bien pequeño: entre 80 y 160 acres; se puede afirmar que la agricultura comercial propiamente dicha no se desarrolló sino hasta después de la construcción del canal Todo Americano. La llegada de agua federal no se utilizó para nivelar, extender y consolidar el patrón de la granja familiar. En cambio, la inversión de capital federal fue un estímulo para el desarrollo del capitalismo agrario en gran escala en el Valle Imperial. "La aprobación del Proyecto Boulder Canyon marcó el inicio, los ranchos de más de 1,000 acres crecieron un 400 o entre 1925 y 1940 . Y con la terminación del canal Todo Americano, los grandes ranchos comenzaron a dominar el panorama de la distribución de la tierra en el valle, al tiempo que aumentaba cl tamaño promedio de los ranchos, aumentaba la concentración de la tierra".46 (Ver cuadro V).

En la cstructura de la tenencia de la tierra del Valle Imperial encontramos tres categorías: propietarios, propietarios parciales y arrendatarios y gerentes. De éstos son los propietarios parciales la clase que ha tenido el más significativo desarrollo durante los últimos cincuenta años. Mientras que en 1920 este grupo concentraba el 12 o/o de la tierra agrícola, con un tamaño promedio para sus ranchos de 258.5 acres, en 1974 el mismo grupo controlaba el $60 \mathrm{o} / \mathrm{d}$ de la tierra con un tamaño promedio para sus ranchos de 1,212.4 acres. ${ }^{4}$ (Ver cuadro VI).

El reporte de la producción agrícola de 1982 marca que en enero de ese año existían 7,005 unidades productivas reportadas, de las cuales el $32 \%$

\footnotetext{
44 Galarza, Ernesto, op, cit., pp. 95 y 57.

45 Idem.

46 Barclay, Bill. State, capital and legitimation crisis: Land and water in California's Imperial Valley, Elseviere, Scientific Publishing Company, 1980. Amsterdam, Pp. 9-10. 4

47 Ibid: p. 11.
} 
CUADRO V. TAMAÑO PROMEDIO Y EXTENSION CUBIERTA POR LOS RANCHOS DE 1,000 ACRES Y MAS, CONDADO DE IMPERIAL, CA. Y ESTADO DE CALIFORNIA

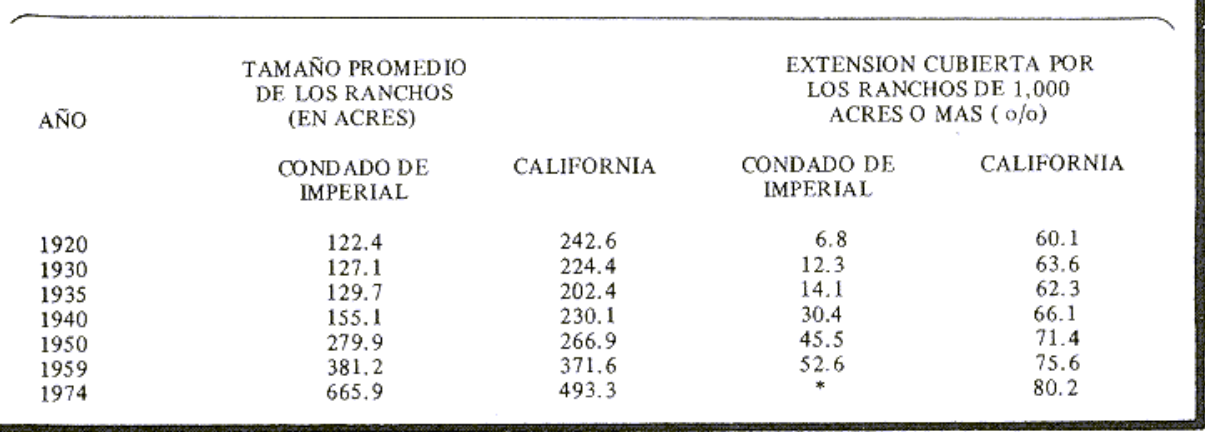

FUENTE: BARCLAY, Bill, Op. cit. p. 9. Calculado en base al Censo Agrícola de los EE.UU., 1920-1974.

CUADRO VI. TAMAÑO PROMEDIO DE LOS RANCHOS Y TENENCIA DE LA TIERRA SEGUN LA CATEGORIA DE LOS OPERADORES. 1920-1974. CONDADO IMPERIAL.

\begin{tabular}{|c|c|c|c|c|c|c|}
\hline \multirow[t]{2}{*}{ AÑ̃ } & \multirow{2}{*}{$\begin{array}{l}\text { PROPIETARIOS } \\
\text { Tamaño promedio } \\
\text { de los ranchos }\end{array}$} & \multirow[b]{2}{*}{$\begin{array}{l}\text { ofo del } \\
\text { total }\end{array}$} & \multicolumn{2}{|c|}{$\begin{array}{l}\text { PROPIETARIOS } \\
\text { PARCIALES }\end{array}$} & \multicolumn{2}{|c|}{$\begin{array}{c}\text { GERENTES Y } \\
\text { ARRENDATARIOS }\end{array}$} \\
\hline & & & $\begin{array}{c}\text { Tamaño } \\
\text { promedio }\end{array}$ & $\begin{array}{l}\text { o/o del total } \\
\text { tierra agr. }\end{array}$ & $\begin{array}{l}\text { Tamaño } \\
\text { promedio }\end{array}$ & $\begin{array}{l}\text { ojo del total } \\
\text { tierra agr. }\end{array}$ \\
\hline 1920 & 97.3 & 32.8 & 258.5 & 12.7 & 126.2 & 54.9 \\
\hline 1930 & 75.9 & 20.0 & 282.5 & 14.8 & 138.4 & 65.1 \\
\hline 1940 & 94.0 & 28.4 & 445.5 & 31.5 & 160.5 & 40.1 \\
\hline 1950 & 152.8 & 28.6 & 595.6 & 40.8 & 285.1 & 28.8 \\
\hline 1959 & 173.3 & 20.0 & 704.5 & 51.8 & 383.8 & 28.2 \\
\hline 1974 & 202.3 & 14.2 & $1,212.4$ & 60.9 & 698.9 & 24.7 \\
\hline
\end{tabular}

FUENTE: Cálculo realizado del Censo Agrícola, 1920-1974. Barclay, Bill, 1980, p. 10. 
eran operadas por propietarios y el 67.9 por arrendatarios. Ya que el reporte sólo incluye estas dos categorías y hace sólo alusión a las unidades operadas y no a las acumuladas, estos datos pueden estar enmascarando las relaciones de propiedad del capital agrario en el valle.

Los contratos de arrendamiento, son una forma de hacerse de tierras en forma rápida y menos costosa. En el valle, comprar un acre de tierra cuesta alrededor de 5,000 dlls, y es difícil hallarla en venta, en cambio, el precio por la renta de un acre oscila entre los 150 y 250 dlls. 48 Otro tipo de contratos son los llamados share-rent, que consisten en el pago de un porcentaje, que puede ir del 20 al $25 \%$. Sin embargo, este tipo de contrato es poco frecuente, dados los riesgos que implica una mala cosecha para el dueño de la tierra. 49

Los contratos de arrendamiento están muy ligados al ausentismo de propietarios en el valle. En los censos de 1925 a 1945 , se reportaba que la mitad de las tierras operadas por los propietarios parciales, era de propietarios ausentes. Tenneco, Southern Pacific RR, United Fruit, Kaiser Aetna, Irvine Land Co. y otras son algunas de las empresas involucradas en la agricultura del valle. 50

Bajo esta organización de tenencia de la tierra. existen en el valle 447 firmas que han sido tradicionalmente consideradas como agrícolas, 51 mientras que de las compañías productoras de hortalizas y legumbres, hay alrededor de 45. Destacan, por el volumen de su producción y por las cantidades de mano de obra que utilizan, las siguientes: Sun Harvest Inc., Abbati Producers, Irvine Co., Maggio Sales, Mario Saikon Inc., Northon Co., Bud Inc., Goumet Farm, Desert Gowers, y Bruce Church Inc. entre otras. El área de operaciones, en gran parte de los casos no se limita al Valle Imperial, sino que cubre otros lugares de California y Arizona principalmente.

Actualmente el Valle Imperial está ubicado entre los 5 primeros condados del estado de California en producción agrícola; es un importante productor de ganado, trigo, alfalfa y remolacha, de los intensivos de capital. En lo referente a cultivos intensivos en mano de obra, Imperial produce: lechuga, brócoli, espárrago, tomate, cebolla, melón y sandía entre los principales, mismos en que se emplean los transmigrantes.

El cuadro VII muestra el valor de la producción por tipo de producto para los años de 1974 a 1981. En ella se destaca la producción de pasturas y gramíneas como las principales aportadoras de ingresos; le siguen en impor-

\footnotetext{
48 Entrevista De la Vega Farms, 1982, Calexico, Ca.

49 Entrevista Leonardo Quiroz, julio 1982, Calexico, Ca.

50 Barclay, Bill, op. cit., 11-12.

51 Abresch. T. Ted, et al. Imperial County agricultural ocupation study, Rural Economic Institute, Washington, D.C. 1981, p. 4.
} 
CUADRO VII. VALOR DE LA PRODUCCION POR TIPO DE PRODUCTO.CONDADO DE IMPERIAL,CALIFORNIA (MILES DE DOLARES)

\begin{tabular}{|c|c|c|c|c|c|c|c|c|c|c|c|c|c|c|c|c|}
\hline AÑO & 1974 & $\mathrm{o} / \mathrm{o}$ & 1975 & o/o & 1976 & o/o & 1977 & o/o & 1978 & o/o & 1979 & o/o & 1980 & $\mathrm{o} / / \mathrm{o}$ & 1981 & o/o \\
\hline Apicultura & 1,102 & 0.2 & 1,047 & 0.2 & 960 & 0.2 & 876 & 0.2 & 1,313 & 0.3 & 1,874 & 0.3 & 1,720 & 0.2 & 1,410 & 0.2 \\
\hline \multicolumn{6}{|l|}{ Pasturas y } & & 186,408 & 42.6 & 240,876 & & 232,527 & 31.2 & 400,043 & & & 44.1 \\
\hline $\begin{array}{l}\text { Frutas y } \\
\text { Nueces }\end{array}$ & \multicolumn{13}{|c|}{ Frutas y } & & & 0.8 \\
\hline \multicolumn{17}{|l|}{ Ganado y } \\
\hline Lácteos & 155,182 & 28.0 & $\begin{array}{r}127,224 \\
\text {. }\end{array}$ & 25.4 & 113,432 & 21.8 & 101,670 & 23.2 & 117,571 & 22.3 & 235,300 & 31.5 & 195,220 & 26.0 & 225,990 & 29.5 \\
\hline $\begin{array}{l}\text { Semillas y } \\
\text { de Viveros }\end{array}$ & 11,870 & 2.0 & 10,780 & 2.2 & 15,355 & 2.9 & 9,040 & 2.1 & 10,971 & 2.1 & 19,615 & 2.6 & 25,699 & 3.3 & 36,412 & 4.8 \\
\hline $\begin{array}{l}\text { Hortalizas } \\
\text { y legumbres }\end{array}$ & 102,763 & 18.4 & 142,288 & 28.4 & 121,806 & 23.4 & 135,301 & 31.0 & 148,835 & 28.4 & 252,331 & 33.8 & 127,582 & 16.7 & 157,456 & 20.6 \\
\hline TO TA L & 557,123 & 100 & 500,202 & 100 & 520,707 & 100 & 437,160 & 100 & 524,414 & 100 & 746,370 & 100 & 757,185 & 100 & 764,862 & 100 \\
\hline
\end{tabular}

FUENTE: Oficina del Comisionado Agrícola. Condado de Imperial, California, Reportes Anuales: 1974-1981. 
tancia las hortalizas y legumbres, producción que en 1979 fue tan elevada que superó el valor de los cultivos intensivos en capital, alcanzando ese año los 252.3 millones de dólares, lo que equivale al 33 o/o del total.52

Es de notar que del total de tierras cultivadas entre 1975 y 1980 , alrededor del $10 \%$ se dedicaron al cultivo de hortalizas y legumbres, y no obstante la reducida superficie destinada a dichos cultivos, representaron aproximadamente el 30 o del valor de la producción del condado en el período 1977-1980. Esto se aprecia al comparar el cuadro VIl con el VIII.

Otro aspecto que se debe tener en cuenta para evaluar la importancia de la producción de verduras en el valle, es que se realiza en época de invierno, en contraste con el resto del país, donde las bajas temperaturas impiden el crecimien to de casi cualquier producto.

Efectivamente, la región donde se ubica el Valle Imperial es capaz de producir y de surtir al país de una gran variedad de verduras, bajo condiciones tan especiales que agregan valor a sus productos.(Ver gráfica 1).

Por último, el carácter intensivo de mano de obra de las hortalizas y legumbres las convierte en las primeras generadoras de empleo. Prucba de ello es que durante 1981, 4 de cada 10 empleos en el condado Imperial fueron proporcionados por la actividad agrícola. El mismo año, de un promedio de 15,600 trabajadores que se emplearon en este sector, el 80.9 o/o formó parte de la categoría de agricultores y trabajadores agrícolas. 53 Los datos expuestos permiten apreciar dos cuestiones fundamentales; el peso de la actividad agrícola para la economía local, y la producción de hortalizas y legumbres como altamente dependientes de la mano de obra de los transmigrantes.

los transinigrantes.

Un importante indicador del peso de la agricultura como actividad generadora de empleo se obtiene al comparar las tasas de desempleo registradas en los meses de enero, cuando la agricultura alcanza su punto más agudo y las de agosto, mes en que la actividad desciende notablemerte. El siguiente cuadro ilustra lo anterior.

\footnotetext{
52 Agriculture crop report: Production and valuation, 1974-1981, County of Imperial, 1981.

53 Overall Economic Development Program, 1982, County of Imperial, p. 44 y 45.
} 
TASAS DE DESEMPLEO PARA ENERO Y AGOSTO DE 1979 Y 1980

\begin{tabular}{lcccr}
\hline & & 1979 & \multicolumn{2}{c}{1980} \\
& Enero & Agosto & Enero & Agosto \\
& 46,850 & 44,900 & 40,400 & 46,850 \\
Fuerza de trabajo civil & 37,650 & 38,850 & 33,200 & 32,950 \\
Empleo & 9,200 & 14,050 & 7,200 & 13,900 \\
Desempleo & 19.6 & 31.3 & 17.8 & 29.7 \\
\hline
\end{tabular}

FUENTE: Employment Development Department, State of California News Release No. 332, 2 de julio de 1982, Sacramento, Ca.

Como resultado de la situación anterior, durante los meses de verano se aprecia un considerable incremento en el número de solicitudes de seguro de desempleo el cual baja en los meses de invierno (ver gráfica 2). Esto también revela el carácter estacional de la agricultura en el valle, y por ende, la incstabilidad de empleo para el transmigrante.

La contratación de mano de obra.

Uno de los aspectos más interesantes y a la vez característico de esta frontera es el que se refiere a la contratación de la mano de obra de los transmigrantes residentes de Mexicali, necesaria para las distintas etapas de la producción agrícola del valle.

La contratación de esta mano de obra se realiza por dos vías fundamentales ${ }^{4}$. Una a través de contratos colectivos de trabajo entre la United Farm Workers, UFW (Unión de Campesinos de América) y las empresas agrícolas, y la otra a través de los contratistas de mano de obra que operan en el valle como intermediarios entre el agricultor y los trabajadores.

La primera forma señalada incluye naturalmente a los trabajadores afiliados al sindicato, los cuales son la minoría y no tienen que pasar por la incertidumbre de conseguir el empleo del día. Sin embargo, en los meses malos, también ellos ocasionalmente se suman al complejo mecanismo de contratación de los no sindicalizados. Por el segundo medio de contratación se incorpora más del $70 \%$ de la fuerza de trabajo agrícola del valle. El contratista de mano de obra es por lo general una persona de ascendencia mexicana, que en algu-

54 Los datos que se exponen en relación a la contratación fueron obtenidos tanto de entrevistas con agri. cultores, contratistas, mayordomos y trabajadores como de observación 


\section{CUADRO VIII. ACRES DEDICADOS POR CULTIVO O ACTIVIDAD CONDADO DE IMPERIAL}

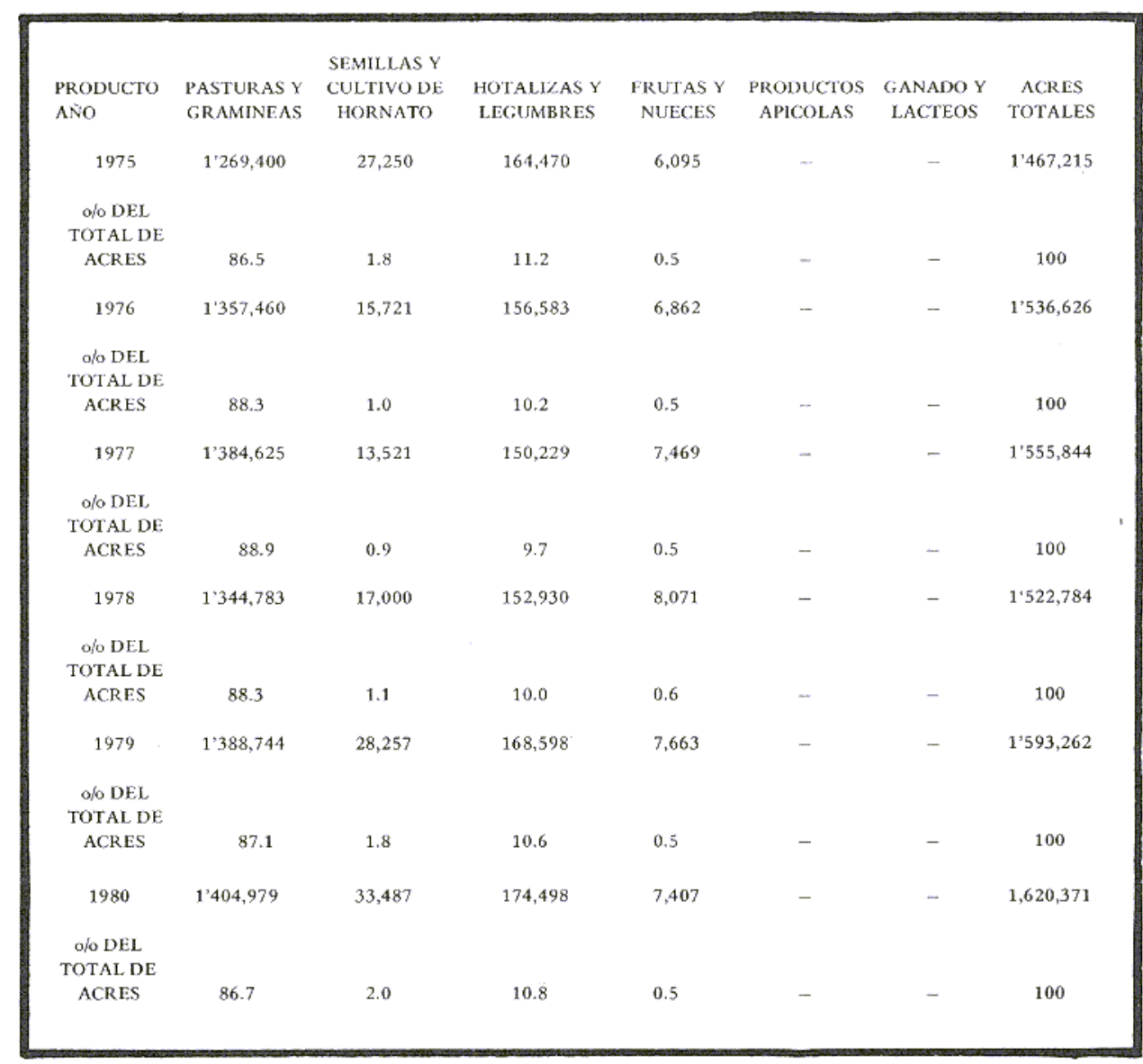

FUENTE: Oficina del Comisionado Agrícola. Condado de Imperial, California. Años: 1975-1980. 


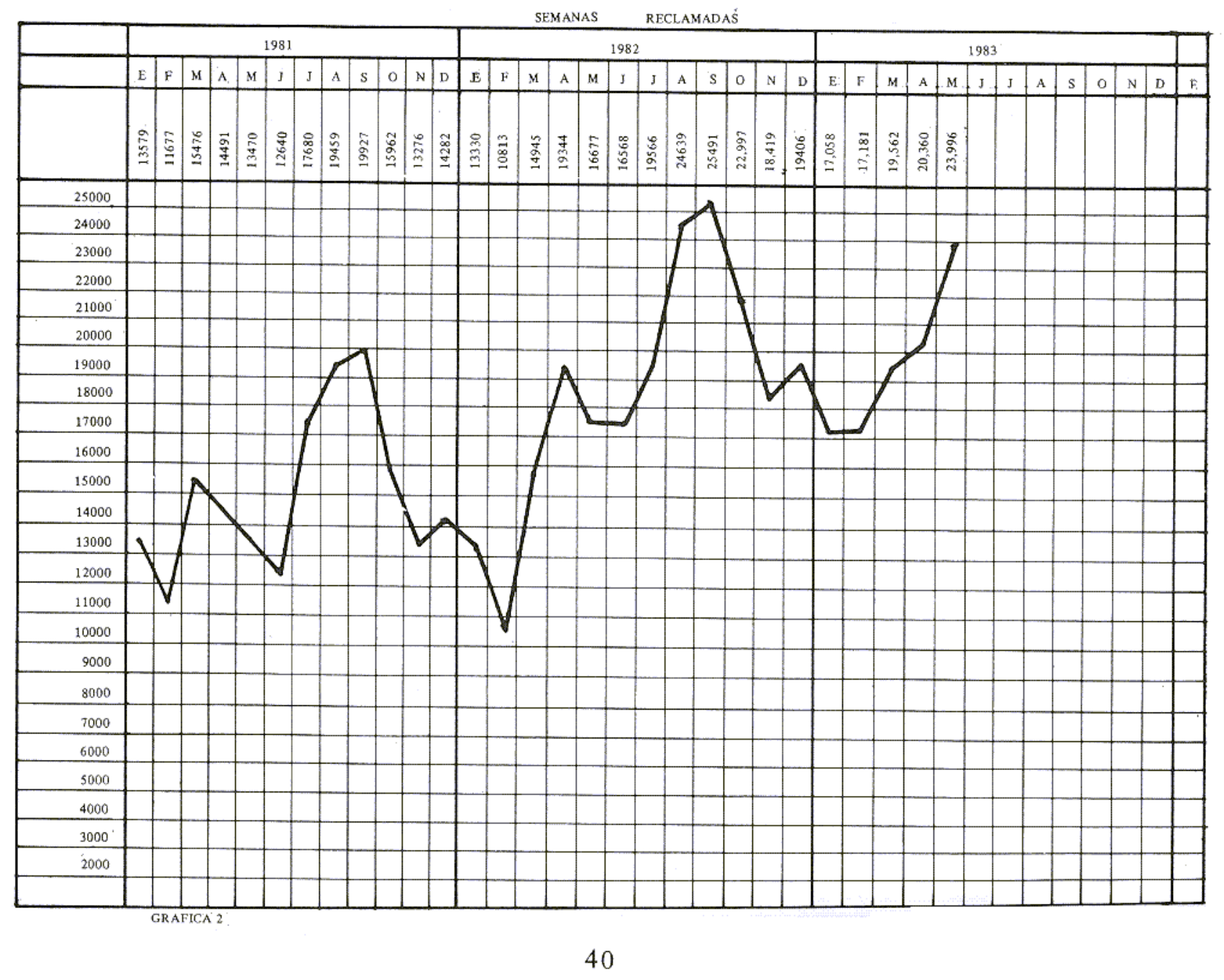




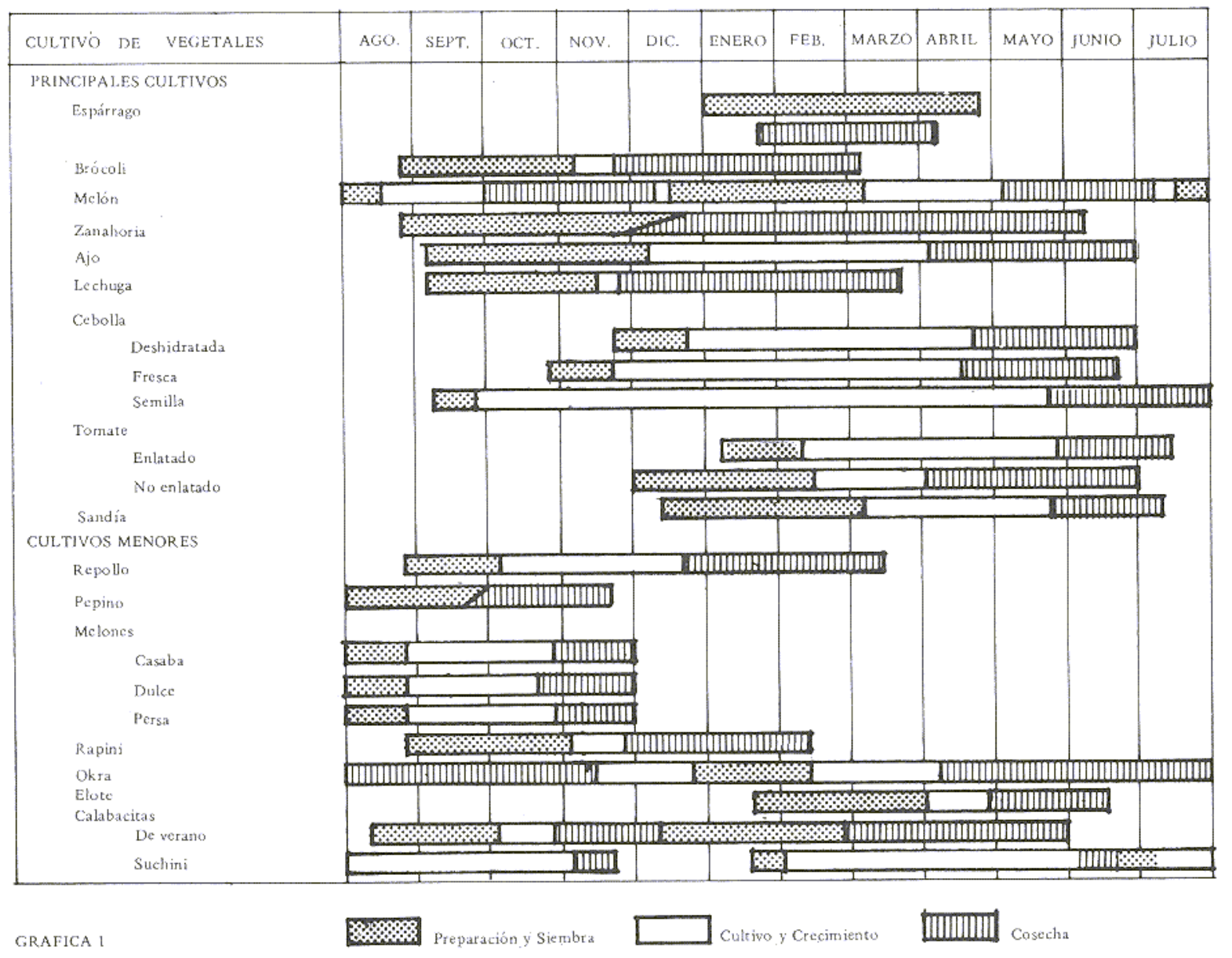


nos casos formó parte del Programa de Braceros y cuyas funciones se resumen en la contratación, traslado, supervisión y pago de los trabajadores. Debe aclararse que existen compañías que no emplean ninguna de estas dos vías para el empleo de fuerza de trabajo, sino que la propia empresa contrata directamente a los trabajadores que acuden a sus oficinas; no obstante, se trata de un procedimiento poco usual.

De los procedimientos mencionados, es el de los contratistas de mano de obra el más destacado y digno describir, por las peculiaridades que presenta.

Quienes viven en esta frontera, saben de la existencia de los "emigrados", - green cards, también saben que ellos cruzan la "línea" en la madrugada pará ir a trabajar "al otro lado". Pero la mayoría desconoce el fenómeno a profundidad. Diariamente, entre las 2 y 5 de la mañana, miles de trabajadores agrícolas transmigrantes realizan el trayecto de sus casas en Mexicali a sus trabajos en el Valle Imperial. Largas filas de carros se forman para cruzar la frontera, lo mismo que varios miles de trabajadores cruzan a pie. Todos van hacia cl gran centro de contratación en que, a esas horas, se convierte la avenida Imperial de la ciudad de Calexico. Ahí, los mayordomos, quienes se emplean para los contratistas, esperan con sus camiones en sitios establecidos para trasladarlos a los campos ubicados en ocasiones a más de dos horas de camino. Los criterios para la contratación dependen del mayordomo, él es quien decide si acepta o no al transmigrante. El trabajador que tiene cierto tiempo residiendo en Mexicali ha llegado a conocer a los diferentes contratistas y mayordomos, lo mismo que éstos a los trabajadores regulares, de tal forma que ambos cuentan con sus preferencias para el trabajo. Sin embargo, estas preferencias no garantizan ni al transmigrante el trabajo de la semana, ni al mayordomo que aquél se presentará al día siguiente, ya que no existe un compromiso escrito ni verbal que obligue a alguna de las dos partes a volver a emplear o volver al empleo al día siguiente. Ciertamente, quien consigue trabajo al inicio de la semana lo más probable es que lo conserve hasta el sábado que es en general el día de pago.

El mayordomo tiene sólo la obligación de explicar, al momento de la contratación, el cultivo en cuestión, el tipo de trabajo a realizar, el lugar donde se requiere, el salario y la forma de pago 55 . Reunido el número de cuadrillas solicitadas previamente por el agricultor, el mayordomo transporta a los trabajadores a los campos de cultivo.

Por otra parte, el arreglo entre el contratista y el agricultor o la empresa, se lleva a cabo en forma verbal y se respeta. En el arreglo se establece el porcentaje que recibirá el contratista por sus servicios y el cual oscila entre el 31 y el 40 por ciento; excepcionalmente encontramos un $45 \%$. El agricultor determina el tipo de trabajo requerido, el número de cuadrillas, el

${ }^{55}$ En términos generales, las escardas y desahijes se pagan por hora y las cosechas a destajo. 
Salario y el tipo de pago. Respecto al salario, cabe notar que aunque existe un salario mínimo en el condado, que en 1982 era de 3.35 dlls. la hora, el ranchero o la empresa pagan un poco más, desde 3.50 hasta 5.00 dlls. en algunos casos. Los servicios del contratista son de gran ventaja para el agricultor, ya que lo desliga del trato directo con los trabajadores, así como de los procedimientos y papeleo que involucran los mecanismos de contratación. Esto no implica por supuesto que el agricultor no supervise el trabajo que se hace en sus campos.

En efecto, "el contratismo en el trabajo agrícola en ningún momento dejó de ser otra cosa que un conveniente arreglo con una considerable flexibilidad moral, legal, económica y social trabajando al servicio de los patrones agrícolas. Probablemente nunca desaparecerá de la escena" 56.

Existen en el valle por lo menos 20 contratistas de mano de obra, entre los que destacan por el volumen de trabajadores que emplean: Don P. Currier, Joe Anaya, Manuel Rodríguez, Constantino Martínez, Joe Ramírez, Yolanda Muñoz, Juan Chávez, Joe Estrada y J \& J Contractors, entre los principales. La mayoría de ellos opera todo el año, a diferente ritmo y en etapas distintas y cultivos diversos. Su área de operaciones abarca frecuentemente otros valles aparte del de Imperial, como Palo Verde, Coachella, Bakersfield, Mendoza y Riverside.

El volumen de trabajadores empleados por los contratistas varía y depende de la época del año. En promedio, los contratistas emplean entre cuatro y cinco mil trabajadores al año. Sin embargo, existen algunos contratistas que en algunos años ha llegado a emplear hasta diez mil trabajadores al año 57 .

En términos generales, los servicios del contratista son más solicitados por las pequeñas y medianas empresas que por las grandes compañías, ya que éstas están en mejor posición de realizar contratos colectivos de trabajo con la United Farm Workers, que aglutina a la mayoría de los campesinos sindicalizados.

En relación a dicho sindicato, se logró detectar una tendencia por parte de empresas y agricultores en general, a evitar contratos con la UFW, debido a los antecedentes de luchas sindicales en el valle que afectaron los intereses de algunas compañías.

Efectivamente, la UFW ha jugado un papel predominante en la lucha por los trabajadores agrícolas de los EE.UU. especialmente en los estados del Suroeste. Una de las conquistas más importantes de esta organización fue la aprobación del Acta de Relaciones Laborales Agrícolas en 1975, en la que

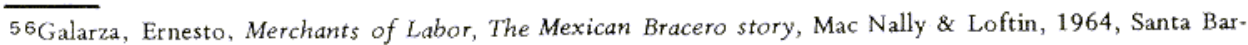
bara, Ca. p. 58 .

57 Entrevista con Manuel Rodríguez, contratista, agosto, 1982, Brawley, Ca. 
por primera vez se reconoce el derecho de sindicalización a estos trabajadores, se les conceden beneficios como el seguro de desempleo, seguro médico, días festivos obligatorios, vacaciones y facilidades de agua y sanitarios durante el trabajo 58 .

Una de las mejores pruebas del impacto que ha resultado de la acción de la UFW en el Suroeste de los EE.UU. es la creación en 1975, en el Valle Imperial, de la Southern California Grower Foundation, 59 que opera como una aseguradora que beneficia a los trabajadores agrícolas que se emplean para los miembros de dicha agrupación. La finalidad de la Southern California Grower Foundation es doble; por un lado, ofrecer a los trabajdores servicios equivalentes a los de un sindicato, y por otro, el más importante, ofrecer al agricultor una alternativa para que éste no se vea obligado a realizar contratos colectivos de trabajo con la UFW 60 . Sin duda, esta empresa es reflejo de que en alguna medida, las luchas de la UFW y su dirigente César Chávez, han creado una preocupación entre los agricultores sobre su trato hacia el trabajador, aunque no necesariamente refleje un auténtico reconocimiento de los derechos de los trabajadores.

No se cuentan con datos suficientes sobre el funcionamiento de la empresa mencionada, sin embargo consideramos posible que esté incidiendo en el proceso de sindicalización en el valle, el cual es, como veremos, notablemente débil a decir por el bajo número de sindicalizados.

\section{EL PERFIL DEL TRANSMIGRANTE *}

Para la exposición de los hallazgos de la encuesta, nos proponemos describir el perfil "ideal" del trabajador transmigrante que reside en Mexicali, B. Cfa. y que trabaja en el Valle Imperial en labores agrícolas, probablemente en él descubriríamos las siguientes características.

Para empezar se trata de un hombre $(87.5 \%)$, casado (63\%), entre los 20 y 34 años $(48 \%)$ o bien mayor de $35(47.3 \%)$, en cuanto a sus estudios nos sorprenderá que no sólo terminó primaria y comenzó la secundaria (39\%) sino que posiblemente haya logrado la preparatoria y realizado otros estudios (22.9), sería raro que nunca hubiera estudiado $(10.5 \%)$.

Por otro lado, en cuanto a su lugar de origen, dependerá mucho de la edad. Si es mayor de 35, será originario del centro del país (42\%) (de Jalisco, Michoacán, Guanajuato, Sinaloa, Sonora o Zacatecas); pero en cambio, si es menor de esa edad, habrá nacido en Baja California (35.5\%). Los padres del transmigrante agrícola habrán trabajado también en este tipo de tareas en México o EE.UU. ( $81 \%)$ y en muchos casos también sus hermanos $(58.5 \%)$.

\footnotetext{
58 Entrevista con Gilberto Rodríguez, encargado de la oficina de la United Farm Workers, en Calexico, 1983.

59 Entrevista con Charles Hewtt, gerente de la Southern California Grower Foundation, agosto 1982.

60 Idem.

* Los datos presentados en este apartado, son resultado de las encuestas aplicadas a los transmigrantes agrícolas, durante 1982 y 1983 . Ver apéndice metodológico.
} 
Respecto a sus antecedentes laborales en México es de esperar que si es originario del centro del país y tenía edad de trabajar, antes de venirse haya trabajado en tareas agrícolas (41.3) como jornalero $(31.5 \%$ ) o en caso excepcional como propictario de tierras $(4.7 \%)$ o ejidatario (5.1), y que al venirse a Baja California ya tuviera intenciones de trabajar en el Valle Imperial $(47 \%)$. Si se trata de una persona joven entre 20 y 34 años es poco probable que haya trabajado en labores agrícolas $(25 \%)$. En cambio, si tiene entre 50 y $54(46.5 \%)$ o si está entre los 55 y $59(58 \%)$ habrá mayores probabilidades y con más razón si es mayor de 59 (70.5\%). Esto implica que conforme aumente la edad, aumentan las posibilidades de que tenga experiencia en estas tareas.

En términos generales habrá trabajado en México (67\%) en tareas agrícolas exclusivamente $(28 \%)$ o combinadas $26 \%)$. Pero es también posible que nunca hubiera trabajado en el campo $(46 \%)$. Lo anterior significa que la hipótesis planteada en el sentido de que el transmigrante de esta frontera posee una amplia experiencia en este tipo de tareas sería parcialmente verdadera, ya que resulta probada en los de mayor edad, y no así con los menores de 34. Esto es, a menor edad, menor experiencia en tareas agrícolas. Lo interesantc es que estos datos están revelando la presencia de un nuevo tipo de trabajador o una nueva generación de transmigrantes agrícolas procedentes de zonas urbanas, con mayor nivel de escolaridad y con poca o nada experiencia agrícola en México.

En cuanto al tipo de trabajo realizado en los EE.UU., es de esperar que sólo hayan sido agrícolas (55\%) por un período mayor a los 7 años $(70 \%)$ y que hayan vivido hasta en tres diferentes lugares de ese país (51\%), aunque tal vez nunca haya vivido allá $(26 \%)$. En lo que se refiere a su trabajo actual, está empleado en general en tareas que no exigen mucha capacitación técnica, tales como desahijador (30.8), cortador (35.3), cargador (5.2) y rara vez como mayordomo $(1 \%)$, operador de máquinas $(1 \%)$, supervisor $(.2 \%)$ u otros menos significativos.

Debido al carácter estacional de la agricultura de la región se empleará entre 4 y 6 meses en el Valle Imperial $(46.2 \%$ ), o entre 7 y 9 meses (27.7), mientras que de manera general en los EE.UU. trabajará más de 7 meses $(64.7 \%$ ). Si se trata de un hombre mayor de 40 años dedicará más meses del año al trabajo agrícola (ya que es el trabajo en que tiene experiencia); sin embargo, el más joven dedicará menos tiempo a esas labores y podrá emplearse como trabajador "circulante", cuando desciende la actividad agrícola del vaue. su experiencra le dice que en el Valle Imperial el trabajo es más intensivo que en otros lugares de California y de EE.UU. en general. En sus palabras:

"En otras partes no exigen tanto trabajo ni tanta prisa".

"Allá trabajan más despacio, por eso a la gente que va de aquí la prefieren por horas. ." 


\begin{abstract}
"Mire, aquí en el Valle Imperial es mucha la diferencia porque aquí si hay presión en el trabajo, allá arriba puede trabajar 10 horas y no se cansa igual que aquí trabajando ocho".
\end{abstract}

Probablemente el transmigrante nunca ha trabajado como indocumentado en EE.UU. (73\%). Y ha pasado más de 10 años viviendo en Mexicali y trabajando en el Valle Imperial $(55.5 \%)$; esto es, como transmigrante.

Probablemente nuestro transmigrante no esté sindicalizado $(75.5 \%)$ y si lo está, pertenece a la UFW $(82.5 \%)$. Generalmente tendrá muy poca o nada de experiencia política en México: lo más seguro es que nunca haya participado en luchas campesinas ni en movimientos sindicales (94\%), que no pertenezca a ningún partido político $(88.5 \%)$, que nunca asista a manifestaciones o mítines $(93 \%)$ y que no desee incorporarse a ningún sindicato $(53.5 \%)$.

Sin embargo, si resulta afiliado a la UFW, su participación será de buen nivel, asistirá a juntas (84\%) intervendrá en discusiones $(55 \%)$ comentará con amigos del sindicato ( $81 \%$ ) habrá participado en luchas laborales $(74 \%)$ y estará satisfecho de pertenecer a la UFW por considerar que ha mejorado su situación $(90.6 \%)$.

En este punto debemos hacer una reflexión, sobre la actuación política del transmigrante en el momento de su incorporación al mercado de trabajo norteamericano y su participación en sindicatos y movimientos laborales como manifestación de una creciente toma de conciencia político-sindical, que fue planteada como hipótesis de la investigación. Evidentemente, con los datos expuestos no resulta verdadero el planteamiento anterior. Aunque se debe reconocer que quienes sí están afiliados al sindicato, manifiestan un alto grado de participación y conciencia de su papel dentro del sindicato. El bajo nivel de sindicalización entre los transmigrantes agrícolas puede tener su explicación en los siguientes factores.

Primero, la United Farm Workers que aglutina a la mayoría de los trabajadores sindicalizados, establece que tienen prioridad para el empleo quienes tienen mayor "señoría", es decir mayor antigüedad dentro del sindicato. Por lo tanto, en los períodos de escasez habrá muchos que tendrán que esperar a que les llegue el turno. Esto puede ser visto como una desventaja para los trabajadores de reciente afiliación, lo que detiene al trabajador a incorporarse al sindicato.

Segundo, la residencia del transmigrante en el lado mexicano de la frontera implica que la reproducción de su fuerza de trabajo y los costos de mantenimiento se realicen a un costo mucho menor que quienes residen en EE.UU. Este hecho podría influir para que el trabajador no sienta necesario afiliarse a un sindicato para obtener mejores salarios, y mejores condiciones de trabajo. 
Por último, el que parece ser a nuestro juicio el más importante elemento: la inestabilidad de las condiciones en que se encuentra el transmigrante en los EE.UU., lo cual ya ha sido observado en apartados anteriores, le provoca un sentimiento de profunda inseguridad que lo limita para manifestar cualquier inconformidad por temor a que el gobierno le retire su tarjeta migratoria.

El salario del transmigrante dependerá definitivamente de su carácter de sindicalizado o no. Si está sindicalizado tendrá un ingreso promedio de 269 dlls. a la semana y en caso contrario serán 180 dólares semanales. Cuando se encuentra desempleado recurre al seguro de desempleo (72\%), cuya cuota es en términos generales de menos de 200 dólares a la quincena (no sindicalizados) y entre 201 y 399 dlls. quincenales (sindicalizados).

Respecto al gasto de este trabajador, es interesante notar que desde la devaluación del peso mexicano, ha reorientado su gasto hacia México, destinando en bienes de consumo básico y equipamiento para el hogar un $60 \%$ a Mexicali y el $40 \%$ restante a la ciudad de Calexico.

Hay muchas probabilidades de que nuestro transmigrante viva en alguna de las siguientes colonias de Mexicali: Baja California (17.3\%), Pueblo Nuevo $(14.3 \%)$, Nueva Esperanza $(7 \%)$, Orizaba $(5.5 \%)$, Cuauhtémoc $(4.3 \%)$, Pro-Hogar $(4.3 \%)$. Dentro de su colonia conoce a un promedio de ocho transmigrantes $(70.5 \%$ ) con los cuales convive frecuentemente $(86 \%)$. En suma, el transmigrante se relaciona y crea amistades entre los propios compañeros de trabajo $(79 \%)$, no así en EE.UU.

Aunque ticne también amigos en ese país $(81 \%$ ) no los visita con frecuencia $(55 \%)$ y en general utiliza muy poco servicios norteamericanos como clínicas $(10.7 \%)$, bancos $(21.6 \%)$, escuelas $(4.1 \%)$. En cambio, es religioso $(66.5 \%)$ ) asiste a la iglesia en México $(91.7 \%)$, a los bancos mexicanos $\langle 61.8 \%)$, a clínicas mexicanas $(87 \%)$ y a las escuelas mexicanas $(94.5 \%)$.

El transmigrante prefiere en general pasearse y divertirse en México: cine $(65 \%)$, días de campo $(94 \%)$, juegos deportivos $95 \%)$, paseos al mar $(93 \%)$ billares $(90 \%)$ y bares $(94.5 \%)$ son sus distracciones principales aparte de visitas $(93.5 \%)$.

El ingreso en dólares de este trabajador le permite un satisfactorio nivel de vida, no obstante que su salario puede ser la única fuente de ingreso familiar $(50.5 \%$ ) y que viven con él un promedio de cinco personas. Es probable que tenga casa propia (54\%) o que pague una renta hasta de 4,000 pesos al mes $(93 \%)$, poco onerosa en relación a su salario. La construcción puede ser de adobe o ladrillo (72\%), muy adecuados para el clima de la región, el cual también exige de refrigeración o abanico que seguramente tiene la casa del trabajador $(90 \%)$. En ocasiones podrá gozar de otros satisfactores como ca- 
rro (55.5\%), televisión ( $92 \%)$, tocadiscos $(67 \%)$. En general, se puede decir que el transmigrante satisface en forma aceptable las necesidades básicas de su familia.

En suma, el transmigrante orienta sus relaciones hacia el lado mexicano de la frontera donde reside, y donde satisface la mayor parte de sus necesidades; sin embargo, aunque aparentemente goza de una situación envidiable en cuanto a ingreso, las condiciones de su trabajo, su inestabilidad en el empleo, su indefinida calidad migratoria y los efectos que se le atribuyen en las ciudades fronterizas norteamericanas, constituyen serias desventajas para este trabajador.

\section{CONCLUSIONES Y PERSPECTIVAS}

La información recabada a lo largo de este estudio, aunada a los resultados de la encuesta, nos ha permitido comprobar la existencia de un doble mercado de trabajo en el condado de Imperial originado por la oferta de mano de obra de los transmigrantes agrícolas residentes en Mexicali, lo que propicia una depresión en los niveles salariales y condiciones de trabajo locales. Efectivamente, hemos visto que más del $85 \%$ de la mano de obra agrícola empleada en el valle proviene de los transmigrantes. Sumado a lo anterior, los datos de la encuesta han revelado además un importante hecho que incide directamente en esta situación: la segmentación al interior de esta oferta externa, como resultado de la falta de organización sindical del $75.5 \%$ de los transmigrantes agrícolas. El bajo grado de sindicalización en este grupo contribuye a mantener el bajo nivel de salarios en la medida que la oferta de trabajo más amplia la conforman los no sindicalizados, de modo que el agricultor o la empresa, se encuentran en una posición de ventaja para establecer, dentro de ciertos márgenes legales, los salarios y condiciones de trabajo que más convienen a sus intereses.

Por lo tanto, la oferta de trabajo externa representada por los transmigrantes agrícolas tiene un doble efecto. Por un lado, como mercado de trabajo paralelo al nacional, deprime los salarios de la zona y por otro, dada la segmentación en su interior, refuerza el mantenimiento de estos salarios al presentar una amplia oferta de trabajo carente de organización.

Como se señaló en páginas anteriores, es probable que la Southern California Grower Foundation esté jugando un papel de obstaculización para el proceso sindical en el valle. El hallazgo constituye un elemento sobre el que hay que indagar más y que podría ser explorado en estudios posteriores.

Ahora bien, en cuanto a las perspectivas que se contemplan para esta fuerza de trabajo en lo que respecta a seguir encontrando empleo en el condado de Imperial, la mecanización podría ser vista como una vía por la cual 
se eliminaría esta mano de obra. Si bien en sus inicios la mecanización * implicó desplazamientos considerables de trabajadores, conforme se avanzó en el proceso y en el conocimiento de sus repercusiones, se hizo evidente que la introducción de tecnología en la agricultura no resolvía todo el problema y que en cambio provocaba trastornos $\mathrm{c}$ inconvenientes que no resultaban costeables en muchos casos.

Veamos en forma breve algunas de las principales implicaciones de la mecanización y de la posibilidad de introducirla en los cultivos del Valle Imperial donde se emplean los transmigrantes.

Por mecanización de la cosecha se entiende la sustitución de las manos de los trabajadores por máquinas como medio para colectar el cultivo 61 . Sin embargo, debe tenerse presente que la mecanización de la cosecha de frutas y hortalizas implica más que la sustitución de los trabajadores manuales por máquinas. El proceso implica una modificación en casi todos los aspectos de la producción, desde la siembra, el manejo del producto y la presentación del mismo.

No sólo se debe diseñar la máquina para el cultivo, sino que el cultivo debe adecuarse a los requerimientos de la máquina a través de largos procesos de modificación genética hasta conseguir que la planta resulte con las características necesarias para la cosecha mecanizada.

La tecnología de cultivo en surco, que es el tipo de cultivo que predomina en el valle, está orientada hacia el logro de una maduración uniforme en el producto que permita que la cosecha mecanizada se realice de una sola "pasada", con el fin de reducir los gastos. Esta tecnología se está convirtiendo en intensiva en capital y requiere de sustanciales insumos del petróleo, además de reducir la demanda de mano de obra en las etapas de deshierbar y escardar. El surcado preciso, la aplicación de fertilizantes y la siembra se diseñan para dar a cada planta las mismas condiciones de crecimiento 62. La mecanización implica también una modificación en el manejo del producto: actualmente las frutas y hortalizas son transportadas en recipientes cada vez más grandes y muchos productos deben someterse a condiciones ideales de enfriamiento antes de ser enlatadas, con objeto de preservar su calidad 63.

En cuanto al producto final, es fundamental tener presente su deterioro ya que con la mecanización se desperdicia gran parte del producto a la vez que se maltrata. Los cultivos cosechados mecánicamente generalmente inclu.

61 Barnet, Paul, et al., Labors Dividing Harvest, California Institute of Rural Studies, 1978, Davies, Ca., p. 49. 62 Ibid. pp. 26-49.

63 Ibid. pp. 30-31.

*Una información más detallada al respecto se encuentra en Barnet, Paul, et al. Labors Divindling harvest, California Institute of Rural Studies, 1978, Davies, Ca. 
yen más pedacería y basura que los cosechados a mano, por ello se requieren procedimientos especiales en el procesamiento y empaque, para seleccionar los mejores productos. Estos hechos han contribuido a la tendencia a sustituir los productos frescos y cosechados a mano por los procesados y cosechados con máquinas 64 .

Por supuesto que para que la mecanización convenga, la tecnología deberá ser ahorradora de costos, deberá costar menos que el trabajo manual que reemplaza. Para ello deberá por tanto considerarse también que con la mecanización se sufre una pérdida de valor en el producto. "La cosecha mecanizada es generalmente menos precisa y cuidadosa que la cosecha manual. Los daños y la inclusión de la tierra son problemas comunes que hacen que los cultivos cosechados mecánicamente sean menos valiosos que cantidades comparables de cultivos cosechados a mano" 65. Además, las cosechadoras recuperan menos cultivo que los trabajadores manuales. Varios recorridos de cosecha manual permiten cosechar el cultivo en grado óptimo de madurez, cosa que no ocurre con la cosecha mecanizada, pues no admite tal selección y se pierde producción 66 .

En suma, la reducción de la producción y la pérdida de calidad son los principales inconvenientes económicos que obstaculizan la adopción de una nueva tecnología en la cosecha de frutas y hortalizas. Aunado a ésto, los requerimientos específicos de la cosecha mecanizada hacen que ésta sea sólo adaptable a ciertas áreas de cultivo.

Otro efecto derivado de la mecanización es la desaparición de los pequeños productores, quienes no estarán en condiciones de competir con los productores mecanizados 67 . En cuanto a la fuerza de trabajo, se reduce el empleo de trabajadores agrícolas primero en las áreas que se mecanizan y posteriormente en áreas vinculadas a aquellas que no resultan competitivas para los productos manuales. Del mismo modo, la mecanización no sólo desplaza mano de obra sino que modifica el carácter del trabajo, cambian los métodos de contratación, de pago, condiciones de trabajo y habilidades del trabajador, al tiempo que se observa un aumento de riesgos y de lesiones para el trabajador 68 .

Si bien la introducción de tecnología en numerosos cultivos ha sido notable en los últimos veinte años, las implicaciones y consecuencias derivadas de la misma nos conducen a pensar que en el caso del Valle Imperial no son superables a corto ni mediano plazo y que además no compiten con las actuales condiciones de la producción local. Esto debido a las siguientes razones: 1)

\footnotetext{
64 Ibid. p. 33.

$65 \mathrm{Ibid}$. p. 40.

66 lbid. pp. 40-41.

67 Ibid. pp. 44-45.

$68 \mathrm{Ibid}$. p. 56.
} 
características de la producción de hortalizas y legumbres que crecen en la región y, 2) ubicación geográfica del valle.

En cuanto al primer punto deben considerarse tres cualidades de esta producción: 1) tipo de cultivos, 2) destino de la producción y, 3) condiciones en que se realiza.

Respecto al tipo de cultivos, las frutas, hortalizas y legumbres que crecen en el valle son de tales características que no existe aún la máquina capaz de mecanizar su cosecha, ni la variedad que admita tal mecanización. Productos como el brócoli, la lechuga, la sandía, el melón, etc, requieren para su cosecha de una decisión subjetiva que una máquina no está en condiciones de realizar, exigen de un juicio humano y de una técnica que por el momento sólo el hombre posee. Aún aceptando que se pudiera lograr ¿en qué tiempo y a qué costos se conseguiría la modificación genética de estos productos?, ¿qué inversión requeriría el diseño y operación de la misma?

Pero pasemos al siguiente punto, el destino de los productos. El Valle Imperial produce para el consumo de productos frescos y no para posteriores procesos. Esto exige del producto una presentación y calidad óptimas que, como vimos, sacrifica la cosecha mecanizada. ¿Convendría al agricultor la pérdida de valor de su producto si además consideramos otro factor?: las circunstancias en que crecen estos cultivos del valle. A diferencia del resto de los EE.UU. o de la mayor parte del país, en el Valle Imperial la cosecha de hortalizas y legumbres se lleva a cabo en los meses más fríos, circunstancia extraordinaria que agrega valor a los productos locales, que de esta forma no tienen competencia significativa en el mercado. Con la mecanización, el agricultor del valle perdería calidad y por tanto valor en sus productos, o bicn tendría que dirigir su producción a otros mercados que no le ofrecerían las ventajas descritas. Ante la situación planteada, no parece conveniente para los agricultores y las empresas introducir maquinaria en estos cultivos, si además existe un último elemento que cierra el círculo en forma ideal para el agricultor: la ubicación geográfica de Imperial. Esta le permite al agricultor disponer de una permanente y amplia oferta de trabajo a costos que no compiten con los que significaría la mecanización. Como hemos señalado en varias ocasiones, la mano de obra agrícola del valle es la de los transmigrantes residentes de Mexicali, quienes además significan para EE.UU. un importante ahorro en la reproducción social de su fuerza de trabajo.

Ante el panorama expuesto, estimamos poco probable y conveniente para la agricultura de Imperial la introducción de tecnología en sustitución de mano de obra. Prueba de ello es que la mecanización en esta área ha ocurrido muy lentamente y sólo en ciertas etapas posteriores a la cosecha; especialmente los procesamientos de empaque se han modificado y siempre con la finalidad de preservar al producto en las mejores condiciones posibles. 
Las dificultades inherentes al proceso de mecanización de la cosecha, los costos, las repercusiones en otras áreas de la producción, los inconvenientes económicos, nos permiten afirmar que no compiten con las actuales condiciones de la producción agrícola del valle y que no sería a corto ni mediano plazo éste el medio por el cual se desplazará al tansmigrante agrícola de esta frontera.

Desde nuestro punto de vista, donde existe un mayor riesgo para los transmigrantes agrícolas está en las políticas migratorias de los EE.UU. y aún parece poco probable un cambio en este sentido.

Las audiencias a que hemos hecho alusión con anterioridad pusieron de manifiesto que existen numerosos grupos que se oponen al sistema de transmigrantes. Entre los argumentos más poderosos manejados por sus opositores, el del desempleo fue uno que contaba con la fuerza suficiente para haber conseguido algún tipo de acción por parte del gobierno para restringir o cancelar el sistema de commuters. Sin embargo, no se tomó ninguna medida al respecto. A esto hay que agregar que desde 1967, año en que surgió la controversia sobre los transmigrantes en forma generalizada, han surgido tres propuestas encaminadas a regular, restringir o cancelar el sistema de transmigrantes y tampoco ha ocurrido nada. Esto prueba, como hemos señalado, que hay muchos intereses de por medio y que los transmigrantes están bien representados en los centros de decisión política del país. Hay que observar que los EE.UU. han cnsayado con otro tipo de trabajadores agrícolas, y que a juicio de la gran mayoría de los agricultores, no existe un trabajador más productivo, más eficiente y más hábil, ni mas "apto" para las tareas agrícolas que el mexicano. Por lo tanto, sería absurdo pensar en cancelar el sistema de transmigrantes para tener que importar mano de obra de otra nacionalidad. Por esto es que aún considerando el sesgo que ha tomado en los últimos dos años la política migratoria de los EE.UU. -léase Proposición Simpson-Mazzoli aprehensiones, deportaciones y agresiones a indocumentados-, no consideramos muy factible, no por ello imposible, que surgicra una legislación en contra del transmigrante. Reconozcamos que su situación siempre ha sido muy inestable, insegura y desventajosa, y que en cambio le es de gran beneficio a ese país.

No obstante llegado el momento, si EE.UU. decidiera cancelar, restringir o regular el sistema de transmigrantes, debemos pensar en cuáles serían los efectos para las comunidades mexicana y norteamericana, ya que no serían los mismos ni de igual magnitud para uno y otro país.

En cuanto a la comunidad norteamericana, podemos suponer que serían dos los efectos que se desprenderían de una cancelación o restricción al sistema de transmigrantes. Por un lado, la falta de empleo de todos o una gran parte de los transmigrantes se traduciría en una disminución de su poder de compra, lo que a su vez se traduciría en una reducción de las compras que ha- 
ce este grupo en los EE.UU. El efecto neto sería, en cuanto a comercio se refiere, una reducción sustancial de dicha actividad que conduciría a una depresión de la economía fronteriza vecina. Por el otro, se generaría un mayor número de empleos disponibles para los trabajadores nacionales, disminuyendo posiblemente el índice de desempleo, con lo que, al menos en teoría, el segundo efecto podría neutralizar el primero, ya que los nuevos empleados aumentarían su capacidad de compra beneficiando al comercio y la cconomía en general. Sin embargo, si partimos de la base de que los trabajadores nacionales no desean aceptar los trabajos de los transmigrantes, ni los sucldos de éstos, seguramente el efecto sería mucho más serio, pues para que los patrones lograran ocupar los puestos vacantes de los transmigrantes, se verían obligados a subir los sucldos desatándose un desequilibrio en la conomía, pues afectaría directamente a la actividad agrícola, base económica de la región de Imperial.

En cuanto a la comunidad mexicana, y en concreto para Mexicali, hemos realizado una estinación cconómica de lo que significaría la cancelación del sistema de transmigrantes en estos momentos (1983).

Los datos que presentamos, están basados en las estimaciones sobre el numero de transmigrantes en esta frontera, y el porcontaje cmpleado en agricultura, según el SIN, así como en los datos derivados de la encuesta, sobre ingresos y las cifras del tabulador del Departamento de Empleo y Trabajo donde se establecen las cuotas quincenales que debe recibir el trabajador que se encuentra desocupado. Para tal estimación, * se tomaron en cuenta las siguientes variables: a) Número de transmigrantes en esta frontera, que se emplean en labores agrícolas, $12,750.6$; b) Número promedio de sindicalizados y no sindicalizados, 3,188 y 9,562 respectivamente; c) Promedio de meses trabajados al año (sindicalizados y no) 7 y 8 respectivamente; d) Ingreso promedio mensual de ambos grupos: 1,076 y 722 dlls.; e) Recepción de seguro de desempleo según el tabulador: 214 y 150 dlls. mensuales, por meses no trabajados, cuatro los sindicalizados y cinco para los no sindicalizados, cn promedio.

De los datos anteriores resulta un ingreso de 30.17 millones de dólares al año para los sindicalizados y 55.97 millones de dólares para los no sindicalizados; esto arroja un total de 86.14 millones de dólares como ingreso anual global de los trabajadores agrícolas transmigrantes de esta frontera (ver cuadros IX y X). La cifra considera los descuentos por concepto de impuestos al gobierno.

De otra parte. la cncuesta aplicada en marzo del presente año reveló que el 60 o/o del gasto que realiza el transmigrante en bienes de consumo bá-

\footnotetext{
* Las cifras pueden ser consideradas como conservadoras, pues hemos tomado siempre el número menor de las estimaciones, a falta de datos más precisos.
} 
CUADRO IX. INGRESO PROMEDIO ANUAL INDIVIDUAL DEL TRABAJADOR AGRICOLA TRANSMIGRANTE DEL CONDADO DE IMPERIAL (EN DOLARES)

\begin{tabular}{lcccccc}
\hline & & & & NO. PROMEDIO & BENEFICIO & INGRESO \\
& NO. PROMEDIO & INGRESO & DE MESES CON & MENSUAL CON & INDIVIDUAL \\
DE MESES & PROMEDIO & SEGURO DE & SEGURO DE & PROMEDIO \\
CATEGORIA & TRABAJADOS & MENSUAL & DESEMPLEO & DESEMPLEO & ANUAL \\
Sindicalizados & 8 & $\$ 1,076.00$ & 4 & $\$ 214.00$ & $\$ 9,464.00$ \\
No Sindicalizados & 7 & 722.00 & 5 & 160.00 & $5,854.00$ \\
& & & & & & \\
\hline
\end{tabular}

FUENTE: Instituto de Investigaciones Sociales-UABC Proyecto: El Trabajador Agrícola Transmigrante 1983.

El Trabajador Agrícola Transmigrante 1983.

CUADRO X. PROMEDIO DEL INGRESO GLOBAL ANUAL DE LOS TRABAJADORES AGRICOLA EN EL CONDADO DE IMPERIAL (EN DOLARES)

\begin{tabular}{cccc}
\hline & NUMERO DE & & \\
TRANSMI- & INGRESO PROMEDIO & INGRESO GLOBAL \\
CATEGORIA & GRANTES & ANUAL & ANUAL \\
Sindicalizados & 3,188 & $\$ 9,464$ & $\$ 30,171,232$ \\
No Sindicalizados & 9,562 & $\$ 5,854$ & $\$ 55,875.948$ \\
TOTAL & & & $\$ 86,147,180$ \\
\hline
\end{tabular}

FUENTE: Instituto de Investigaciones Sociales, UABC, Proyecto: El Trabajador Agricola Transmigrante, 1983.

* El número de transmigrantes agrícolas se obtuvo en base a la cifra estimada por autoridades del Servicio de Inmigración v Naturalización que es de 15.000 transmigrantes en esta frontera, de los cuales el $85 \%$ se dedican a tareas agrícolas, lo que da un total estimado de 12,750. La proporción de sindicalizados y no sindicalizados se obtuvo de la encuesta $25 \%$ y $75 \%$ respectivamente. 
sico y equipamiento para el hogar, lo efectuaba en el lado mexicano de la frontera, mientras que el 40 o/o restante permanecía en EE.UU. Sin considerar que el transmigrante gasta una importante suma en México por concepto de vivienda, educación, salud, servicios y otros, puesto que es aquí donde radican, trasladando los porcentajes señalados al ingreso global anual de este grupo resulta una cifra de 51.68 millones de dólares para México y 34.45 millones para EE.UU. Los 51.68 millones de dólares traducidos a pesos al tipo de cambio $150 \times 1$ equivalen a una derrama de 7,753.24 millones de pesos al año para la economía de nuestra ciudad. (Ver cuadro XII).

Así, la cancelación del sistema de commuter afectaría la economía local al dejar de percibir 7,753.24 millones de pesos al año. Aunado a ésto, se desataría un problema de desempleo que afectaría a miles de familias pues según la encuesta, en el 51 o/o de los casos los transmigrantes resultaron ser la única fuente de ingreso familiar.

Finalmente deseamos hacer una última observación. El porcentaje del gasto que el transmigrante destina actualmente a México refleja en cierta medida una relación de competitividad entre los mercados de Imperial y Mexicali. Podemos afirmar que hasta marzo de 1983 (mes en que se aplicó la encuesta), el mercado de Mexicali competía ventajosamente en un $60 \%$ con el de la vecina ciudad. Sin embargo, creemos que esta proporción se verá reducida o transferida al mercado de Calexico, en la medida que el mercado local mexicano no ofrezca mayores ventajas. No será necesario que exista una paridad en los precios a ambos lados de la frontera, ya que el diferencial, cuando éste dejara de ser significativo, se compensaría con la calidad, presentación y variedad de los productos norteamericanos.

Estimamos que la presencia del transmigrante en la frontera afecta en forma diferente a ambos países, sin embargo, creemos que en estos momentos es más benéfica para México. Es posible esperar que el trabajador transmigrante seguirá con su mismo patrón de empleo mientras exista una agricultura en el Valle Imperial que demande esta mano de obra barata y cuyos costos de reproducción corren por cuenta de México.

La respuesta al doble mercado de trabajo creado por este flujo laboral hacia EE.UU. no está en su cancelación, sino en la organización sindical de estos trabajadores. De ahí que las organizaciones laborales y especialmente la United Farm Workers, reconozcan la importancia de su tarea para lograr dicho objetivo, con lo que se conseguiría no sólo mejorar los salarios, condiciones de trabajo y nivel de vida de sus afiliados, sino la dignificación de todo el trabajador agrícola de esta frontera, donde el transmigrante mexicano contribuye en buena medida al sostén y desarrollo de la economía agrícola del Valle Imperial. 
Sin temor a equivocarnos, pensamos que conocer el tema de la transmigración es indispensable para entender la vida fronteriza del norte de México y cuya riqueza no ha sido agotada en este trabajo, que por ser el primero que se realiza para esta frontera, adolece de muchas fallas y limitaciones. Con todo y eso, representa el inicio de una larga $\mathrm{c}$ interesante tarea de explorar una dimensión tan poco conocida de la frontera.

\section{APENDICE METODOLOGICO}

Las categorías empleadas en el análisis para el logro de los objetivos y la comprobación de las hipótesis fueron las siguientes: desarrollo desigual y combinado, migración. internacionalización del trabajo, acumulación de capital, explotación del trabajo y reproducción social de la fuerza de trabajo.

A nivel empírico se efectuaron: un sondeo en 1981 de 60 cuestionarios; 25 entrevistas estructuradas a especialistas, funcionarios públicos, cmpresas agrícolas, agricultores, contratistas mayordomos, dirigentes sindicales y 14 entrevistas profundas a transmigrantes agrícolas para obtener información que la encuesta no lograba captar; dos encuestas, una en marzo de 1982 y la segunda en el mismo mes de 1983.

La primera encuesta se levantó en un período de tres semanas, a una muestra de 400 transmigrantes. La varianza del ingreso fue la base para determinar el tamaño de la muestra, con un $95 \%$ de confianza y $10 \%$ de precisión. El cuestionario incluyó 100 preguntas. ${ }^{*}$ La población se captó en la ciudad de Calexico, Ca. entre las 3 y 6 de la mañana, en el cruce fronterizo de peatones y los sitios de contratación establecidos sobre la avenida Imperial, principal eje de la ciudad de Calexico, así como en el llamado "hoyo", punto de reunión de los trabajadores sindicalizados.

La segunda encuesta se aplicó partiendo de la necesidad de actualizar información esencial para el análisis del fenómeno. Se consideró que los cambios en la política económica de México y los efectos de la última devaluación habrían incidido en el comportamiento y situación de los transmigrantes, lo que era preciso conocer.

El grado de homogeneidad en el ingreso de este grupo permitió la obtención de una muestra de 125 cédulas, 100 a trabajadores no sindicalizados y 25 a sindicalizados. ${ }^{*}$ El cuestionario incluyó diez preguntas sobre aspectos básicamente económicos que permiticron apreciar cambios con respecto al año anterior. Al igual que la primera encuesta la población se captó cn los mismos lugares y bajo los mismos criterios de selección. ***

\footnotetext{
* Los aspectos abarcados fueron: características demográficas, orígenes socioeconómicos, historia laboral, participación política y sindical, condiciones de trabajo, red de relaciones sociales y condiciones de vida.

** La distinción entre sindicalizados y no sindicalizados, obedeció a que una vez analizada la primera encuesta se descubrió la importanica de hacer tal discriminación.

*** El criterio fue aplicar el cuestionario al primer trabajador que llegara al punto señalado.
} 
CUADRO XI DISTRIBUCION DEL GASTO DE LOS TRANSMIGRANTES AGRICOLAS EN MEXICO Y EE.UU. POR TIPO DE PRODUCTO

\begin{tabular}{lcccr|}
\hline CONCEPTO & MEXICO & $\%$ & EE.UU. & $\%$ \\
& 55 & 13.75 & 45 & 11.25 \\
Alimentos & 55 & 13.75 & 45 & 11.25 \\
Ropa & 50 & 12.50 & 50 & 12.50 \\
Aparatos eléctricos & 80 & 20.00 & 20 & 5.00 \\
Muebles & 240 & 60 & 160 & 40 \\
TOTAL & & & \\
\hline
\end{tabular}

CUADRO XII. DESTINO DEL SALARIO DEL TRANSMIGRANTE AGRICOLA (MILLONES)

\begin{tabular}{|lrrr|}
\hline País destino del salario & \% Salario & Dólares & Pesos \\
& & & \\
MEXICO & $60 \%$ & 51.68 & $7,753.24$ \\
ESTADOS UNIDOS & $40 \%$ & 34.45 & $4,168.83$ \\
TOTAL & $100 \%$ & 86.14 & $12,922.07$ \\
\hline
\end{tabular}

